\title{
Aproximación al contenido de un Derecho Constitucional al medio ambiente*
}

\author{
Manuel José Terol Becerra** \\ Catedrático de Derecho Constitucional \\ Universidad Pablo de Olavide
}

Recibido: 20.07.2011

Aceptado: 21.11.2011

\begin{abstract}
Resumen: El silencio de la Constitución española respecto al significado de la expresión "medio ambiente" ha propiciado la elaboración de construcciones teóricas sobre su concepto, sumamente extensas. En ellas aquél concluye identificándose con la naturaleza y ésta con una realidad indivisible y en peligro, además, como consecuencia de la actividad humana. Tan amplias son dichas construcciones que se revelan inapropiadas para proponer, con su ayuda, posibles contenidos de un futuro derecho subjetivo al "medio ambiente". Con mayor motivo si se estima que su objeto reclamaría la parcela de bienestar autónoma invocada por el artículo 45 de la Constitución, con exclusión de cualquier otra disposición constitucional, de tal modo que permita a sus titulares vivir con comodidad, sin molestias para sus personas ni merma para sus bienes y reaccionar frete a las injerencias de terceros en dicho sosiego. De donde se sigue la negación a la actividad protectora estatal de la naturaleza de toda consideración medioambiental.
\end{abstract} raleza.

Palabras Clave: Medio ambiente, derecho subjetivo, conservación de la natu-

Abstract: The silence of the Spanish Constitution regarding the meaning of the term "environment" has prompted the development of theoretical constructs about its concept over an extremely long time. They identified the environment as the "nature", which is with an inseparable reality and in danger as a result of human activity. These theoretical constructs are broad and therefore inappropriate to propose possible meaning of a subjective right to the "environment". More so if the objective is to reclaim an autonomous wellbeing right invoked in Article 45 of the Constitution, with the exclusion of any other constitutional provision, thereby enabling their holders to live in comfort, without interference with their persons or the reduction of their goods and react against the interference of third parties in that peacefulness. From this follows the denial of the state's protection of the nature of any environmental consideration.

Key Words: Environment, subjective right, nature conservation.

" Una primera versión del presente trabajo fue publicada con el título: "Conservación de la naturaleza versus al derecho al medio ambiente", en la obra colectiva, dirigida por Antoni Pigrau Solé y Lucía Casado Casado: Derecho ambiental y transformaciones de la actividad de las administraciones públicas. Barcelona, Atelier, 2010.

** Investigador principal del Proyecto de Excelencia P07-SEJ- 3112: "La construcción del Estado Social en el ámbito autonómico y europeo". 
SUMARIO. I. Introducción. II. Propuesta metodológica de aproximación al significado constitucional del medio ambiente. III. El derecho al medio ambiente y la protección de la naturaleza como realidades jurídicas diferenciables. Mención de sus tratamientos estatutarios. IV. Derecho de propiedad versus protección de la naturaleza.

\section{INTRODUCCIÓN}

Sería necio negarle a la Constitución la posibilidad de asignarle significados concretos a sus contenidos. Aunque, bien mirado, no sea cosa suya ni, por tanto, se espera que decida hurtar algunas de sus previsiones a la disponibilidad de los poderes constituidos por ella, esto es, a la oportuna acción concretizadora de las mismas sino excepcionalmente. Según hacen, por ejemplo, todas las Constituciones con sus dictados relativos a las señas de identidad del Estado o, algunas solamente, cuando acogen cláusulas de intangibilidad.

Dicho sea en otros términos, porque el poder constituyente originario es, en esencia, refractario a cualquier clase de limitación, tanto puede emplear fórmulas sancionadoras de interpretaciones específicas para cualquier regulación suya como eludirlas. Si bien se considera aquí inusual la primera opción referida, por la singularidad que representa la inserción del correspondiente enunciado en el contexto de unas disposiciones tan deliberadamente ambiguas e imprecisas como las que usualmente conforman la Constitución. Por eso mismo, favorecedoras de una pluralidad de concretizaciones ciertamente beneficiosas para su permanencia en el tiempo.

Visto así, desde esta perspectiva, nada tiene de particular el que la Constitución española de 1978 se ocupe en su artículo 45 del medio ambiente sin llegar a definirlo, no obstante. Dicho silencio constitucional, unido al de los documentos certificantes de cómo se elaboró la disposición en torno a qué podían referirse sus artífices con la expresión medio ambiente, alienta a pensar en que para el constituyente se trataba de un concepto lo bastante conocido como para no precisar de aclaración. Cuando la realidad era otra, pues hasta 1984 no certificó la vigésima edición del Diccionario de la Real Academia el uso de la expresión entre hispanohablantes; y aunque es verdad que el Decreto 2414/1961, de 30 de noviembre, por el que se aprobó el Reglamento de actividades molestas, insalubres, nocivas y peligrosas ya lo usó, no es posible deducir del mismo ni de ninguna otra norma preconstitucional una idea jurídica, en tanto que normativa, de medio ambiente.

Acaso todo ello le sirvió a la doctrina de acicate para construir los conceptos que, en crecido número, ofreció a su respecto desde poco después de aprobarse la Constitución. Tan extensos siempre que tal vez mediaran otras razones alternativas o añadidas en dicho afán conceptuador. Pues, dígase, cómo calificar de otro modo a un conjunto de conceptuaciones oscilantes entre las que pretenden identificar al medio ambiente con la naturaleza o, mejor, con 
los elementos que seguramente la conforman -discutiendo quienes así piensan si basta con el aire y el agua para componer su noción o debe integrarse en ella, además, el suelo-, y las que sin cuestionar esa identificación de la naturaleza con el medio ambiente, demandan incorporar a su concepto elementos adicionales de carácter económico, social y cultural. Esa indefinición constitucional sobre el medio ambiente tal vez estimulase al Tribunal Constitucional también a construir la noción del mismo que ofrece en la STC 102/1995, de 26 de junio. De todo ello se darán cumplida cuenta éstas páginas más adelante. Antes interesa recordar que la Constitución española vigente se ocupa del medio ambiente en el artículo 45.

A reserva de lo que se diga luego sobre este artículo, merece destacarse ahora cómo su párrafo primero muy bien podría expresar la idea instalada en la conciencia social, cuando se redactó, de asistirse a un deterioro del medio ambiente imputable a la conducta humana. Eso explicaría la doble consideración de derecho y deber que allí recibe. Pero el interés de dicho enunciado constitucional no eclipsa el que aquí tiene el párrafo segundo, que, de un lado, incluye una referencia a la calidad de vida, digna de destacarse por el nexo que, aun en términos ambiguos e imprecisos, contempla entre la misma y el medio ambiente; y que, de otro, impone al Estado las obligaciones de defenderlo y de restaurarlo, comprometiéndolo así con la procura existencial del individuo que escapa a su control.

A cuyo propósito conviene traer a colación que, según García Pelayo, aun cuando sea difícil determinar qué medidas concretas definen la procura existencial, pues depende de las circunstancias, situaciones y coyunturas, cabe identificar como tales, siguiendo a Forsthoff, las actuaciones de la Administración que buscan proporcionar el goce de prestaciones útiles a la generalidad o, en razón de criterios objetivos, a determinados grupos de personas, en ocasiones. Sentado lo cual, añade García Pelayo que, en todo caso, la procura existencial ha de ocuparse, entre otros asuntos, de "la seguridad de los distintos aspectos vitales en la sociedad nacional". De forma que si antes se concretaba en la defensa exterior e interior frente al delito o la subversión del orden establecido, hoy ha de considerársela vinculada con la tutela o amparo del individuo frente a contingencias y necesidades económicas globales, el deterioro del ambiente natural, el agotamiento de los recursos naturales o la radicalización y extensión de los antagonismos en el seno de la sociedad nacional, por ejemplo ${ }^{1}$.

En definitiva, el que la Constitución de 1978 contemple al medio ambiente como una parcela del bienestar ciudadano, alienta a emprender su estudio desde una perspectiva antropocéntrica, en la cual se convierta el individuo en el sujeto de la acción tuitiva estatal frente a las alteraciones que

${ }^{1}$ Cfr. Manuel García Pelayo: "El Estado social y sus implicaciones". Las transformaciones del Estado contemporáneo. Madrid, Alianza, 1977 (1982,3ª ed. Corregida y aumentada), pp. 26 a 30. 
en su entorno pueda producirle la actuación de un tercero con merma para su calidad de vida. Eso, exige indagar no tanto respecto a los posibles elementos constitutivos de ese entorno, sino sobre la extensión del ámbito correspondiente a la parcela de bienestar llamada a convertirse en el objeto de la protección del Estado, con la finalidad de acotarla respecto de otras invocadas por la propia Constitución con ese mismo propósito de amparo o tutela estatal, así como, consiguientemente con ello, sobre la clase de alteraciones o molestias que puede conocer el individuo en su medio.

\section{I.1. En torno al significado tradicional y mayoritariamente atribuido al medio ambiente.}

\section{I.1.1. Sobre el silencio de los trabajos constituyentes y de la Constitución en torno a su concepto.}

Del medio ambiente, se ha dicho ya, se ocupa el artículo 45 y más adelante, en el Título VIII, lo menciona el artículo 149.1.23, ninguno de los cuales ofrece explicación alguna sobre el significado de la expresión. En efecto, no lo hace el párrafo primero del artículo 45, que, invoca al medio ambiente para enunciar el derecho a su disfrute, del que todos son titulares, y el deber de su conservación, que obliga a todos también, no sólo a los poderes públicos. Tampoco dice nada respecto al sentido de "medio ambiente" el párrafo segundo del citado artículo 45, emplazamiento constitucional de una interesante relación entre recursos naturales, calidad de vida y medio ambiente.

Completa lo establecido en la disposición constitucional que ahora se comenta, el artículo 45, un postrer párrafo igualmente hermético sobre el significado del medio ambiente. Pues nada dicen sobre el particular sus previsiones, atentas a las posibles vulneraciones de aquel apartado precedente encomienda al legislador la tarea de regular lo atinente a las sanciones penales o, en su caso, administrativas que, según dispone dicho artículo 45.3, ha de corresponder a sus infractores, puntualizando además éste que pesará sobre ellos la obligación de reparar el daño causado.

Todavía menciona al medio ambiente la Constitución en su artículo 149.1.23 entre el elenco de materias llamadas a conformar, en principio, competencias sobre las que le toca decidir al Estado de modo exclusivo. Si bien, como sucede en otros casos enumerados en el artículo 149.1 de la Constitución, dicha reserva competencial a favor del Estado sólo le faculta, en realidad, para adoptar la legislación básica sobre protección del medio ambiente. Pues el propio artículo 149.1.23 permite que las Comunidades Autónomas, con el concurso necesario de sus respectivos Estatutos de Autonomía, claro está, aprueben normas adicionales de protección medioambiental. A todo lo cual añade la disposición que le corresponde también al Estado la potestad para definir la legislación básica sobre montes, aprovechamientos forestales y vías pecuarias. De modo que, como puede comprobarse, nada aclara respecto a la cuestión que interesa dilucidar. Tales son las referencias al medio 
ambiente que realiza la Constitución, silentes todas, como ha quedado dicho sobre el significado de la expresión.

Pero si nada dicen, al respecto, los artículos 45 y 149.1.23 de la Constitución sobre el particular, igualmente inútil es buscar dicho pormenor en los trabajos constituyentes dedicados a la concreta elaboración de las disposiciones citadas y no por ausencia o escasez de fuentes. Faltan, desde luego, los diarios correspondientes a las sesiones llevadas a cabo por la Ponencia Constitucional y por la Comisión Mixta Congreso-Senado. Aunque a pesar de tales carencias es abundante la información que proporcionan las publicaciones oficiales de las Cortes Constituyentes de su tarea. El problema radica en otro sitio y es que nada concluyente al respecto se desprende de los documentos generados por las Cortes durante la elaboración de la Constitución.

No es improbable que quienes redactaron la Norma Constitucional conocieran las ideas de medio ambiente expresadas por organizaciones tales como la Unión Mundial para la Naturaleza, el Fondo Mundial para la Naturaleza o Greenpeace, que, desde antes, identificaban al medio ambiente con la naturaleza y a ésta con una realidad inescindible en parcelas y en peligro además por la acción humana ${ }^{2}$. Pero lo cierto es que durante la elaboración de la Constitución no llegó a manifestarse en las Cortes Constituyentes ninguna clase de consideración relativa al significado de la expresión medio ambiente. Tan impenetrables se muestran las tareas del constituyente sobre la idea o ideas de medio ambiente que circulaban en aquellas Cortes que ni siquiera de los debates conducentes a la aprobación de la disposición que, por sus contenidos, permitían albergar esperanzas al respecto, el artículo 45.2, puede obtenerse información satisfactoria sobre el particular.

\section{I.2. Recordatorio de la actitud doctrinal sobre el medio ambiente poste- rior a la constitución.}

Sea como fuere nada tiene de particular que a fuer de difundir los medios de comunicación dicha visión medioambiental terminara ésta por calar en la opinión pública y, por su intermediación, en el mundo del Derecho. Bastante elocuente del predicamento que tienen en España, desde hace tiempo, tales visiones del medio ambiente es el protagonismo que adquirieron, en ciertas construcciones doctrinales efectuadas con la finalidad de conceptuarlo, no mucho después de aprobarse la Constitución vigente, las evocaciones de lo circundante a los seres vivos, en general y a las personas en particular, como esencia de lo medioambiental. Así, en 1981, afirmaba Martín Mateo que "la palabra ambiente, en términos generales, corresponde a la expresión inglesa

\footnotetext{
${ }^{2}$ Planteamiento este que aún mantienen las organizaciones citadas, como también, por ejemplo, el Instituto World Watch o el Grupo Intergubernamental de Expertos sobre el Cambio Climático.
} 
environment y a la francesa environnement que han sido traducidas con acierto entre nosotros por 'entorno', aunque con evocaciones de carácter urbanístico. Una primera aproximación al concepto de ambiente nos remite a una noción amplia que incluye toda la problemática ecológica general y, por supuesto, el tema capital de la utilización de los recursos a disposición del hombre en la biosfera"3.

\section{I.3. EI medio ambiente jurisprudencial}

\section{I.3.1. De su concepto en la STC 102/1995, de 26 de junio.}

Según todo apunta el Tribunal Constitucional se inspiró en las referidas construcciones doctrinales cuando, luego de renunciar repetidamente a conceptuar el medio ambiente, decidió ofrecer una noción del mismo, bastante acabada por cierto, en la STC 102/1995, de 26 de junio. Desde luego que el Tribunal consultó el Diccionario de la Real Academia. Pero si lo hizo con la aparente intención, como cabía esperar, de aproximarse así a la idea de medio ambiente circulante entre la sociedad y con ello manifestaba su renuncia a dejarse llevar, en este punto, por su criterio de juzgador, exclusivamente, es decir, si buscaba aprehender el significado de la expresión instalado en la conciencia social con algún fundamento, forzoso es reconocer que esos propósitos se vieron eclipsados por el "a priori" doctrinal sustentador de su indagación que acaba de mencionarse.

Antes interesa referir apenas la actitud jurisprudencial aludida, esquiva a la conceptuación del medio ambiente, mostrada por el Tribunal en pronunciamientos anteriores a la STC 102/1995. Pues, en efecto, en las SSTC 64/1982, 69/1982 y 170/1989, hubo de dirimir sendas contiendas competenciales entre el Estado y varias Comunidades Autónomas con el medio ambiente como objeto de las disputas. Lo que hizo sin enunciar, por eso, su concepto en ninguna, limitándose a señalar en la STC 64/1982 que las normas sobre el particular se encontraban "dispersas en leyes referidas a distintas materias. Así, para limitarse a lo que aquí interesa en la Ley de Montes, en la del Suelo (véanse por ejemplo los artículos 8,80 y 82) y en la legislación minera" ${ }^{4}$. Manifestación esta que, a la postre, admite considerarse preludio del

\footnotetext{
${ }^{3}$ Dicho autor se muestra consciente de ofrecer un concepto amplio de medio ambiente, inspirado en declaraciones internacionales dedicadas al mismo, según lo evidencia el que a renglón seguido de tales consideraciones añadiese: "Esta perspectiva globalista es a veces la adoptada en ciertos pronunciamientos realizados en el seno de organismos internacionales. Así, en la Conferencia de Estocolmo de 1972 se afirma que el hombre tiene el derecho fundamental a la libertad, la igualdad y el disfrute de las condiciones de vida adecuadas en un medio de calidad tal que le permita llevar una vida digna y gozar de bienestar, y tiene la solemne obligación de proteger y mejorar el medio para las generaciones presentes y futuras". Cfr. "El ambiente como objeto de derecho". Derecho y medio ambiente. Madrid, Centro de Estudios de Ordenación del Territorio y Medio Ambiente, Ministerio de Obras Públicas, 1981, p. $19 / 21$.

${ }^{4}$ Cfr. STC 64/1982, de 4 de noviembre, F.J. $5^{\circ}$.
} 
concepto sumamente amplio de medio ambiente consignado en la STC 102/1995.

Efectivamente, en dicha Sentencia el Tribunal comenzaba advirtiendo de la dificultad para discernir con la exactitud y el rigor de las categorías jurídicas que pudiera ser el medio ambiente. Aunque no por eso renunció al intento de aprehenderlo ${ }^{5}$. Tarea que acometió recordando que la Constitución Española, "como las demás, utiliza palabras, expresiones o conceptos sin ocuparse de definirlos, por no ser misión suya y cuyo significado hay que extraer del sustrato cultural donde confluyen vectores semánticos ante todo y jurídicos en definitiva, con un contenido real procedente a su vez de distintos saberes y también de la experiencia"6.

Este es el caso del medio ambiente, decía, expresión gramaticalmente redundante y calificable jurídicamente, a su juicio, como "concepto jurídico indeterminado con un talante pluridimensional y, por tanto, interdisciplinar (STC 64/1982)". Visto desde una perspectiva semántica, destacaba la acepción del Diccionario de la Real Academia que define al "medio" como el "conjunto de circunstancias culturales, económicas y sociales en que vive una persona o un grupo humano", aunque para añadir, a renglón seguido, que dicho significado gramatical, no resultaba sin embargo suficiente para "perfilar" el oportuno concepto jurídico que, en su opinión, no comprendía en principio tantos elementos y excluía el componente social ${ }^{7}$.

Por otra parte, estimaba comprensivo el "ambiente" de "las condiciones o circunstancias de un lugar que parecen favorables o no para las personas, animales o cosas que en él están"; así como integrado el "medio ambiente" por el "conjunto de circunstancias físicas, culturales, económicas y sociales que rodean a las personas ofreciéndoles un conjunto de posibilidades para hacer su vida". Las personas, proseguía, "aceptan o rechazan esas posibilidades, las utilizan mal o bien, en virtud de la libertad humana. El medio no determina a los seres humanos, pero los condiciona. Se afirma por ello, que el hombre no tiene medio sino mundo, a diferencia del animal". No obstante, en la Constitución y en otros textos, concluía, "el medio, el ambiente o el medio ambiente (...) es, en pocas palabras, el entorno vital del hombre en un régimen de armonía, que aúna lo útil y lo grato. En una descomposición factorial analítica comprende una serie de elementos o agentes geológicos, climáticos, químicos, biológicos y sociales que rodean a los seres vivos y actúan sobre ellos para bien o para mal, condicionando su existencia, su identidad, su desarrollo y más de una vez su extinción, desaparición o consunción"8.

\footnotetext{
5 "Aun cuando esa dificultad no pueda eximirnos de intentarlo en la medida necesaria para encuadrar la Ley en tela de juicio y analizar luego individualmente los preceptos impugnados", decía. Cfr. STC 102/1995, de 6 de junio, F.J. 4º.

${ }^{6}$ Cfr. STC 102/1995, de 6 de junio, F.J. $4^{\circ}$.

${ }^{7}$ Cfr. Ibíd.

${ }^{8}$ Cfr. Ibíd.
} 
No es dudoso que el Tribunal afirmara esto luego de consultar los enunciados del Diccionario de la Real Academia relativos al medio ambiente. Es más, a juzgar por sus palabras debió ser la edición de 1984 o la posterior de 1992. Pues, no en balde, informaban tales asertos, algo confusamente, desde luego, de las acepciones de "medio", "ambiente" y "medio ambiente" allí consignadas. No muy distintas, es verdad, de las que sobre "medio" y "ambiente" ofreciera en ediciones anteriores, las cuales, como se adelantaba, nada decían de la expresión "medio ambiente". Téngase en cuenta que, desde la edición citada en primer lugar, lo define el Diccionario de la Real Academia como el conjunto de circunstancias físicas que rodean a los seres vivos y, por extensión, el conjunto de circunstancias físicas, culturales, económicas, sociales, etc. que rodean a las personas.

Dígase si no son reconocibles en la referida construcción jurisprudencial tales definiciones semánticas y si no pudo entenderlas el Tribunal tan ambiguas como para moverle a concluir su interpretación gramatical del artículo 45 de la Constitución con una reflexión destinada a destacar la naturaleza antropológica de su objeto de estudio, en los siguientes términos literales:

"El ambiente, por otra parte, es un concepto esencialmente antropocéntrico y relativo. No hay ni puede haber una idea abstracta, intemporal y utópica del medio, fuera del tiempo y del espacio. Es siempre una concepción concreta, perteneciente al hoy y operante aquí'”.

Con todo ello el Tribunal no daba sino un primer paso, en orden a construir el concepto de medio ambiente que ofrecía en la Sentencia. El siguiente le llevaría a consultar con tal motivo la legislación preconstitucional y aun la postconstitucional ${ }^{10}$, antes de manifestar que en el artículo 45 de la Constitución recibe el medio ambiente la configuración plural resultante de revelarse allí los recursos naturales sus elementos integrantes, aunque sin acompañar dicho aserto de aclaración alguna ${ }^{11}$. Acto seguido citaba una serie de recursos

\footnotetext{
${ }^{9}$ Cfr. Ibíd.

${ }^{10}$ La Sentencia informa cumplidamente del camino recorrido al efecto: "Una vez utilizado para desentrañar el concepto jurídico indeterminado del medio ambiente su componente semántico, queda otro camino para indagar cuál sea su contenido, camino que no puede ser otro sino el ordenamiento jurídico, desde donde se llega escalando hasta el nivel constitucional, que a su vez le da su luz propia. Aunque a las veces se hable de la Constitución y del ordenamiento, separándolos aparentemente al juntarlos, la realidad es que componen una estructura inescindible y, por tanto, que la una y el otro se hallan interrelacionados hasta formar una unidad alejada de cualquier dicotomía abstracta. Esto resulta patente en el esquema constitucional de distribución de competencias. Cfr. F.J. $5^{\circ}$ ".

${ }^{11}$ En efecto, según afirmaba "la Constitución, en su art. 45, nos brinda algunos de los elementos del medio ambiente, los recursos naturales, aun cuando tampoco los enumere o defina. Es una noción tan vieja como el hombre, dotada de una sugestiva, aparente y falsa sencillez, derivada de su misma objetividad, mientras que el supraconcepto en el cual se insertan es un recién llegado, complejo y propicio a lo subjetivo, problemático en suma". Cfr. F.J. $6^{\circ}$.
} 
naturales que ya en pronunciamientos anteriores estimó tales, en concreto el aire o la atmósfera, el agua, la pesca marítima, los minerales y la agricultura, para añadir ahora que no sólo la fauna, sino también la flora formaban parte de este conjunto, así como su soporte físico, el suelo (y el subsuelo) y el paisaje $^{12}$. En definitiva, afirmaba, "la tierra, el suelo, el espacio natural, como patrimonio de la Humanidad, produce unos rendimientos o «rentas», los recursos, que son sus elementos y cuyo conjunto forma un sistema, dentro del cual pueden aislarse intelectualmente, por abstracción, otros subsistemas en disminución gradual, hasta la célula y el átomo"13.

Alcanzado este punto ofrecía el Tribunal una definición todavía provisional de medio ambiente, en cuya virtud "estaría compuesto por los recursos naturales (...), con el soporte físico donde nacen, se desarrollan y mueren. La flora y la fauna, los animales y los vegetales o plantas, los minerales, los tres 'reinos' clásicos de la Naturaleza con mayúsculas, en el escenario que suponen el suelo y el agua, el espacio natural. Sin embargo, ya desde su aparición en nuestro ordenamiento jurídico el año 1916, sin saberlo, se incorporan otros elementos que no son naturaleza sino Historia, los monumentos, así como el paisaje, que no es solo una realidad objetiva sino un modo de mirar, distinto en cada época y cada cultura"14.

Sin embargo, el medio ambiente no podía reducirse para el Tribunal a la mera suma o yuxtaposición de los recursos naturales y su base física, pues lo concebía como un entramado producto de la relación entre todos esos elementos. Por decirlo con sus propias palabras, se trataba de "un concepto estructural cuya idea rectora es el equilibrio de sus factores, tanto estático como dinámico, en el espacio y en el tiempo"15.

He aquí completa, por fin, la noción de medio ambiente enunciada en la STC 102/95. Tan amplia, como puede comprobarse que en nada sorprende el discurrir posterior del pronunciamiento por los derroteros de su protección. A cuyo respecto estimará el Tribunal tan digno de tutelarse por el legislador nacional el entorno de sus ciudadanos como cualquiera de los considerados por aquél elementos del medio ambiente. Pues, en efecto, consideraba además el Tribunal que el medio ambiente nació como concepto para reconducir a la unidad los diversos componentes de una realidad en peligro. De tal modo que

\footnotetext{
${ }^{12}$ Noción estética, decía, "cuyos ingredientes son naturales -la tierra, la campiña, el valle, la sierra, el mar- y culturales, históricos, con una referencia visual, el panorama o la vista, que a finales del pasado siglo obtiene la consideración de recurso, apreciado antes como tal por las aristocracias, generalizado hoy como bien colectivo, democratizado en suma y que, por ello, ha de incorporarse al concepto constitucional del medio ambiente como reflejan muchos de los Estatutos de Autonomía que luego se dirán". Cfr. F.J. $6^{\circ}$.

${ }^{13}$ Cfr. Ibíd.

${ }^{14}$ Cfr. Ibíd.

${ }^{15}$ Cfr. Ibíd.
} 
de no haberse presentado el riesgo, estimaba inimaginable su aparición ${ }^{16}$. De ahí que se detuviese a enumerar los factores desencadenantes del mismo y a subrayar su aptitud para manifestarse en un abanico de posibilidades comprensivas de "lo simplemente incómodo a lo letal, con una incidencia negativa sobre la salubridad de la población en la inescindible unidad psicosomática de los individuos ${ }^{17}$.

De tales amenazas procedían para el Tribunal las reacciones jurídicas nacionales e internacionales tendentes a la defensa y protección del medio ambiente, esto es, a su amparo, ayuda, defensa y fomento, guarda y custodia, de manera tanto preventiva como represiva. Pues dicha acción tuitiva apelaba, según decía, a otro concepto jurídico indeterminado, requerido de precisión por las normas y los actos destinados a su ejecución. Tanto más, añadía, cuanto "la acción del hombre con riesgo para el medio ambiente se proyecta en las más variadas manifestaciones, sanitarias, biológicas, industriales o urbanísticas, procedentes del tráfico rodado o del turismo y depredadoras sin más, como la caza y la pesca, manifestaciones difícilmente compartimentables por su heterogeneidad, aun cuando las normas lo intenten hasta donde pueden. Hemos dicho más arriba, y no es inoportuno traerlo aquí, que el carácter complejo y polifacético propio de las cuestiones relativas al medio ambiente hace que éstas afecten a los más variados sectores del ordenamiento jurídico (STC 64/1982)"18.

Pero tantos y tan variados elementos componían la noción de medio ambiente enunciada en la STC 102/95, que muy bien podía incluir ésta, como hacía, un juicio favorable a la consideración constitucional de la medida legislativa prolongadora de la acción tutelante sobre aquél más allá de lo circundante al ciudadano español. No en balde, según afirmaba allí el Tribunal: "Respuesta positiva también en lo esencial, por dirigirse directamente a la misma finalidad tuitiva, merece el supuesto de la «comercialización en vivo o en muerto» de las especies que reglamentariamente se determinen, con una notoria dimensión supranacional. Este control de la comercialización tiene un carácter instrumental, pero con una relación directa, para la protección de aquellas especies cuyo precio en el mercado despierta la avidez y desencadena la agresividad, como ha sido el caso del marfil o las pieles, las grasas y otros

\footnotetext{
${ }^{16}$ Que situaba en "la erosión del suelo, su deforestación y desertización, la contaminación de las aguas marítimas, fluviales y subálveas, así como de la atmósfera por el efecto pernicioso de humos, emanaciones, vertidos y residuos, la extinción de especies enteras o la degeneración de otras y la degradación de la riqueza agrícola, forestal, pecuaria o piscícola, la contaminación acústica y tantas otras. Cfr. F.J. $7^{\circ}$.

${ }^{17}$ Con otras palabras, añadía, "estas disfunciones son las recogidas en el catálogo incluido en el documento de trabajo núm. 4 que el 25 de agosto de 1970 presentó el Secretariado de la C.E.P.E. a la Reunión de Consejeros Gubernamentales en materia del medio ambiente de la Comisión Económica para Europa". Cfr. F.J. $7^{\circ}$.

${ }^{18}$ Cfr. F.J. $7^{\circ}$
} 
productos, que han puesto en peligro al elefante, la ballena o el visón, sin olvidar la deforestación por mor de muy diversos factores"19.

\section{I.3.2. De su sintonía con la conciencia social. Filología del medio ambiente.}

Desde luego que en lenguaje usual el medio ambiente ofrece unos contornos difusos, presentes, acaso inevitablemente, en el tratamiento dispensado por el Diccionario de la Real Academia a la expresión. En el cual, por su parte, se inspira la significación jurídica a su respecto de la STC 102/1995.

Tal vez la ambigüedad mostrada por la comunidad de hispanohablantes con respecto al significado de "medio ambiente", sea el único modo que tiene un grupo no estructurado de expresar la importancia que le concede al asunto. En eso se traduciría la dificultad por conceptuarlo que indica, además, la indeterminación a su respecto. Interesa subrayarlo porque esa actitud social no tiene por qué dificultar, a su vez, la atribución de sentido jurídico al "medio ambiente", con la ayuda, sí, del que ofrece el lenguaje usual, pero no mediante la incorporación sin más del mismo al Derecho. Téngase en cuenta al respecto que en lenguaje usual tanto la expresión "medio ambiente" como las voces que la componen, se emplean para designar el entorno más o menos próximo de una cosa determinada, desde una perspectiva dinámica, esto es, en interacción con él.

No en balde, cuando se ocupa del "ambiente" la vigésima segunda edición del Diccionario de la Real Academia habla del fluido que rodea a un cuerpo, del aire, de la atmósfera y de las condiciones físicas, sociales, económicas, etc., de un lugar, de una reunión, de una colectividad o de una época; al tratar la voz "medio" apela al espacio físico en que se desarrolla un fenómeno determinado, de igual modo que al conjunto de peculiaridades culturales, económicas y sociales en que vive un grupo; y construye el significado de la expresión "medio ambiente" por referencia a las circunstancias económicas, culturales y sociales en que vive una persona, así como a las de carácter exterior a un ser vivo.

Acerca de la expresión "medio ambiente" conviene tener presente que hasta su vigésima edición, en 1984, no la incluyó el Diccionario de la Real Academia entre sus artículos, concretamente en el correspondiente al vocablo "medio"20. Desde entonces y hasta su vigésima primera edición, en 1992, ofrecía dos acepciones de la locución. En la primera la definía como el conjunto de circunstancias físicas que rodean a los seres vivos; y, por extensión, en la segunda, como el cúmulo de circunstancias de esa clase y las culturales, eco-

\footnotetext{
${ }^{19}$ Cfr. F.J. $26^{\circ}$.

${ }^{20}$ Otro tanto hizo el diccionario manual e ilustrado de la lengua española, tercera edición revisada, tomo IV, Madrid, Espasa-Calpe, 1984.
} 
nómicas y sociales circundantes a las personas ${ }^{21}$. Tratamiento este que ha conocido un cambio en su vigésima segunda edición, derivado de alterar la Academia el orden de sus acepciones. De modo que apela ahora la primera al conjunto de circunstancias culturales, económicas y sociales en que vive una persona y la segunda al conjunto de circunstancias exteriores a un ser vivo.

En lo que al medio ambiente se refiere parece ofrecer, pues, la vigésima segunda edición del Diccionario de la Real Academia una visión algo más antropocéntrica de la que anteriormente daba, al tiempo que enfatiza, como hiciera en las ediciones previas referidas, la cualidad de vivo que parece requerir de un sujeto concreto el hispanohablante para referirse a su entorno con la expresión "medio ambiente". De tal modo que éste suele emplear el vocablo "medio" para designar el de las cosas u objetos, pues eso autoriza a sostener el significado que recibe hoy el término, en la vigésima segunda edición del Diccionario, concretamente en su décima quinta acepción, en donde según se adelantaba se le define como el espacio físico en el que se desarrolla un fenómeno determinado. Mientras que, a la vista de los significados atribuidos por el Diccionario de la Real Academia a la voz "ambiente", muy bien podría usarla el hispanohablante como sinónimo de "medio" o de "medio ambiente"

Pero, interesa volver sobre el tratamiento que en esa vigésima segunda edición le dedica el Diccionario al "medio ambiente", para llamar la atención sobre la idea de completitud que en él adquiere el ámbito circundante del sujeto considerado. Bien es verdad que el "medio ambiente" puede adjetivarse. Harto elocuente al respecto es la relación de circunstancias susceptibles de envolver a una persona o a un ser vivo que, a título de ejemplo, menciona el diccionario. Pero es obvio que sin el concurso de una adjetivación, por sí misma reductora de tan amplio significado como el allí atribuido al "medio ambiente", admite éste identificarse con el universo.

Sin embargo, ninguna crítica merece el tratamiento que recibe el medio ambiente en el Diccionario de la Real Academia. Según todos los indicios se limita éste a certificar el significado que tiene la expresión entre los hispanohablantes, coincidente con el que adquieren en sus respectivas lenguas "environnement" o "environment", por ejemplo. Pues la uniformidad de criterio sobre el medio ambiente en las sociedades contemporáneas descansa en una significación del mismo compartida por ellas, referida al entorno de los seres vivos en general y de las personas en particular.

${ }^{21}$ Las ediciones del diccionario académico concernidas por este tratamiento son, además de las ya mencionadas, la del diccionario manual e ilustrado de la lengua española, cuarta edición revisada, Madrid, Espasa-Calpe, 1989; y el diccionario de la lengua española, vigésima primera edición, Madrid, Espasa-Calpe, 1992. 


\section{I.3.3. De su coincidencia con ciertos planteamientos internacionales sobre el medio ambiente.}

No es dudoso que el significado atribuido, en la STC 102/1995, al medio ambiente, es tributario del que le adjudica a éste el Diccionario de la Real Academia. Pero no sólo, pues resulta incontrovertible que en dicho pronunciamiento se erigía el Tribunal Constitucional en portavoz ocasional de la percepción dominante en la sociedad a su respecto. No en balde, conceptuaba allí al medio ambiente como una realidad en peligro, a escala planetaria, y, consecuentemente con ello, se mostraba preocupado por él. En concreto, por cuanto rodea al ser humano, incluidas circunstancias tan accesorias para ese entorno, al menos para el ponderable en el caso de España, como son los elefantes, las ballenas y los visones. Respecto de los cuales expresaba el interés por tutelarlos que le permitía el ordenamiento español, de modo que no estimó censurable la decisión adoptada por el legislador de impedir el comercio de tales especies, de sus grasas, de sus pieles y del marfil. Recuérdese.

Sin embargo, tan impregnada de sociología se advierte la construcción en torno al medio ambiente de la STC 102/1995 que cuesta considerarla producto sólo del influjo en el Tribunal Constitucional de su consideración académica. La noción del mismo que ofrece el Diccionario consiente, desde luego, sostener concepciones amplias a su respecto, pero no sugiere que éstas hayan de incluir elemento alguno ni tampoco, por consiguiente, ninguna especie, animal o vegetal. La fuente inspiradora de tal planteamiento jurisprudencial ha de buscarse en otro sitio. Concretamente en ciertos documentos internacionales de diversa naturaleza. Los cuales si, de un lado, se sustentan en la idea de encontrarse la Tierra en peligro y, por tanto, cualquier entorno humano, debido a la explotación incontrolada de los recursos naturales; de otro y, consiguientemente con ello, pretender contribuir a la defensa de estos últimos, así como de especies difícilmente encuadrables entre esos recursos naturales.

Respecto a este asunto se muestra bastante ilustrativa la "Declaración de la Conferencia de las Naciones Unidas sobre el Medio Ambiente Humano", adoptada en la reunión que a tal efecto tuvo lugar en Estocolmo entre el 5 y el 16 de junio de 1972, al proclamar en su Preámbulo:

"1.El hombre es a la vez obra y artífice del medio que lo rodea, el cual le da el sustento material y le brinda la oportunidad de desarrollarse intelectual, moral, social y espiritualmente. En la larga y tortuosa evolución de la raza humana en este planeta se ha llegado a una etapa en que, gracias a la rápida aceleración de la ciencia y la tecnología, el hombre ha adquirido el poder de transformar, de innumerables maneras y en una escala sin precedentes cuanto le rodea. Los dos aspectos del medio humano, el natural y el artificial, son esenciales para el bienestar del hombre y para el goce de los derechos fundamentales, incluso el derecho a la vida misma”.

Abstracción hecha, tanto del vínculo anudado por la Declaración entre el medio -o, mejor, entre los aspectos natural y artificial del mismo en que allí 
se le descompone- y el bienestar humano, así como de la alusión velada al medio ambiente como una realidad en peligro -más clara en otros pasajes del documento ${ }^{22}$, apenas interesa destacar de la cita cómo se identifica en ella al medio con cuanto rodea al hombre, esto es, con un entorno descrito en términos tan amplios e indeterminados que muy bien admite considerarse equivalente al comprendido por la totalidad de la Tierra. Circunstancia esta que se encargan de confirmar, además del dato, bastante elocuente, relativo al carácter internacional del documento, por demás desprovisto de un objeto que recaiga sobre un territorio concreto, cierto contenido de la Declaración que enseguida se dirá.

En el mismo sentido se pronuncian ciertos tratados internacionales agrupables por la proximidad de sus objetos, de un modo u otro vinculados a la obtención de una buena calidad atmosférica. Tal es el caso del Convenio de Viena para la Protección de la Capa de Ozono, de 22 de marzo de 1985 y de su complemento, el Protocolo de Montreal, relativo a las sustancias que agotan la capa de ozono, de 16 de septiembre de 1986; así como de la Convención Marco de las Naciones Unidas Sobre el Cambio Climático, de 9 de mayo de $1992^{23}$. Ofreciendo también una idea de medio ambiente afín a la enunciada en Estocolmo, la "Declaración de Río sobre el Medio Ambiente y el Desarrollo", gestada en la Conferencia de Naciones Unidas que, con ese mismo nombre, se reunió en Río de Janeiro del 3 al 14 de junio de 1992.

Ninguna duda cabe respecto a la influencia de la Declaración de Estocolmo en el Convenio de Viena para la Protección de la Capa de Ozono. Así lo evidencia el reconocimiento de aquella como fuente inspiradora de los con-

${ }^{22}$ También en su Preámbulo puede leerse: “3. El hombre debe hacer constante recapitulación de su experiencia y continuar descubriendo, inventando, creando y progresando. Hoy en día, la capacidad del hombre de transformar lo que le rodea, utilizada con discernimiento, puede llevar a todos los pueblos los beneficios del desarrollo y ofrecerles la oportunidad de ennoblecer su existencia. Aplicado errónea o imprudentemente, el mismo poder puede causar daños incalculables al ser humano y a su medio ambiente. A nuestro alrededor vemos multiplicarse las pruebas del daño causado por el hombre en muchas regiones de la Tierra, niveles peligrosos de contaminación del agua, del aire, de la tierra y de los seres vivos; grandes trastornos del equilibrio ecológico de la biosfera; destrucción y agotamiento de recursos insustituibles y graves deficiencias, nocivas para la salud física, mental y social del hombre, en el medio por él creado. Especialmente en aquel en que vive y trabaja.

${ }^{23}$ Otro tanto puede decirse de la adición al Tratado conocida con el nombre de Protocolo de Kyoto, de 11 de diciembre de 1997. El cual, retomando las consideraciones vertidas en dicha Convención Marco de las Naciones Unidas Sobre el Cambio Climático, versa sobre el cambio climático planetario y según dicen sus partes signatarias persiguen con él paliar el calentamiento atmosférico, limitando o reduciendo la emisión antropogénea de los gases de efecto invernadero y comprometiéndose al respecto, entre otras cosas, a formular, aplicar, publicar y actualizar programas relacionados con ello en sectores económicos tan diversos como la energía, el transporte, la industria, la agricultura, la silvicultura y la gestión de desechos. 
tenidos integrantes de este último, enunciado en su Preámbulo. El cual dedica a este asunto una afirmación del siguiente tenor literal:

"Recordando las disposiciones pertinentes de la Declaración de la Conferencia de las Naciones Unidas sobre el Medio Humano, y en especial el principio 21, que establece que, de conformidad con la Carta de las Naciones Unidas y con los principios del derecho internacional, "los Estados tienen el derecho soberano de explotar sus propios recursos en aplicación de su propia política ambiental y la obligación de asegurar que las actividades que se lleven a cabo bajo su jurisdicción o control no perjudiquen el medio de otros Estados o de zonas situadas fuera de toda jurisdicción nacional”.

He aquí el contenido de la Declaración de Estocolmo que, según se anunciaba, consiente advertir en ella una idea de medio ambiente identificable con un entorno humano equivalente a la totalidad del planeta. Con él, como puede comprobarse, conecta el Convenio de Viena y ha de entenderse que lo hace igualmente el Protocolo de Montreal, no en balde desarrollo suyo.

También la Convención Marco de las Naciones Unidas Sobre el Cambio Climático, luego de afirmar que "la naturaleza mundial del cambio climático requiere la cooperación más amplia posible de todos los países" ${ }^{24}$, recuerda en su Preámbulo, de una parte, "las disposiciones pertinentes de la Declaración de la Conferencia de las Naciones Unidas sobre el Medio Humano, aprobada en Estocolmo el 16 de junio de 1972", y, de otra, que "de conformidad con la Carta de las Naciones Unidas y los principios del derecho internacional, tienen el derecho soberano de explotar sus propios recursos conforme a sus propias políticas ambientales y de desarrollo, y la responsabilidad de velar por que las actividades que se realicen dentro de su jurisdicción o bajo su control no causen daño al medio ambiente de otros Estados ni de zonas que estén fuera de los límites de la jurisdicción nacional".

Tampoco es dudoso el influjo de la Declaración de Estocolmo en la de Río de Janeiro sobre el Medio Ambiente y el Desarrollo. No en balde, da comienzo ésta a su Preámbulo "reafirmando la Declaración de la Conferencia de Naciones Unidas sobre el Medio Humano, aprobada en Estocolmo el 16 de junio de 1972, y tratando de basarse en ella, con el objetivo de establecer una alianza mundial nueva y equitativa mediante la creación de nuevos niveles de cooperación entre los Estados, los sectores claves de las sociedades y las personas". De ahí resulte familiar la idea de medio de medio ambiente sugerida en el aserto realizado, casi a renglón seguido de dicha afirmación, en los siguientes términos literales: "la naturaleza integral e interdependiente de la Tierra, nuestro hogar"; y que muestre ese mismo sigo evocador la proclamación de su principio séptimo: "los Estados deberán cooperar con espíritu de

24 “y su participación en una respuesta internacional efectiva y apropiada, de conformidad con sus responsabilidades comunes pero diferenciadas, sus capacidades respectivas y sus condiciones sociales y económicas". 
solidaridad mundial para conservar, proteger y restablecer la salud y la integridad del ecosistema de la Tierra”.

\section{PROPUESTA METODOLÓGICA DE APROXIMACIÓN AL SIGNI- FICADO CONSTITUCIONAL DEL MEDIO AMBIENTE}

Resulta pretencioso sostener que el universo -tanto da identificarlo con todo cuanto existe o apenas con la naturaleza- esté en peligro y arrogante o soberbio atribuirle una causa humana, pasando por alto con qué tiranía actúan las leyes del universo o, si se prefiere, de la naturaleza. A este propósito merece recordarse el aserto con que iniciaba Montesquieu Del espíritu de las leyes: "Las leyes en su más amplia significación son las relaciones necesarias que se derivan de la naturaleza de las cosas. En este sentido, todos los seres tienen sus leyes: las tiene la divinidad, el mundo material, las inteligencias superiores al hombre, los animales y el hombre mismo" 25 . Se traen a colación las palabras del citado autor porque, parafraseándolas, puede afirmarse que en los tiempos presentes parece como si el hombre pretendiese sustituir con sus leyes las de la naturaleza, ignorando con ello, acaso deliberadamente, la diferencia que media entre una y otra clase de leyes, pues mientras las leyes humanas pertenecen al mundo deber ser, las otras conciernen al del ser.

Interesaba destacarlo porque, por una parte, la Constitución española vigente, como tantas otras en la actualidad -atinentes todas al deber ser-, declara el derecho al medio ambiente; y porque si por tal se entiende, por otra, el derecho al equilibrio universal -asunto este que concierne al mundo ser-, es obvio que ningún Estado se encuentra en condiciones de obtenerlo ni, por tanto, de tutelarlo. Dicho sea en otros términos, aunque la naturaleza estuviese en peligro y éste procediera del ser humano, se estima aquí que el concepto de medio ambiente resultante de identificarlo con aquella, por inabarcable, no es operativo, en el terreno jurídico ni, por consiguiente, lo es tampoco la idea de construir un derecho subjetivo con la naturaleza como objeto. Por eso, se opta en estas páginas por contemplar al medio ambiente desde una perspectiva distinta de la utilizada hasta ahora, acorde con su consideración de realidad intensamente relacionada con el bienestar humano.

\subsection{El plan constitucional del bienestar}

Toda Constitución se ocupa del bienestar ciudadano. Así ha sido siempre. Al Estado, desde su aparición, le ha encomendado esa tarea, de modo implícito o explícito, la Constitución que lo instauraba. La seguridad, las diferentes clases de libertad y la propiedad que, como derechos, proclamaban

${ }^{25}$ Cfr. Del espíritu de las leyes (traducción de Mercedes Blázquez y Pedro de Vega). Tecnos. Madrid, 1987, p. 7. 
las primeras Constituciones, contribuían, sin duda, a la obtención de bienestar por los ciudadanos. Incluso las respectivas partes orgánicas de aquellas Constituciones, desde el momento en que organizaban el poder político a la medida de la burguesía liberal, limitando su proclividad a expandirse puede decirse que propendían al bienestar humano.

Nada de eso ha cambiado con la Constitución española de 1978. Desde luego que su concreción, en la parte orgánica, del ámbito autorizado al actuar de los poderes públicos que crea beneficia a la seguridad jurídica relacionada con los derechos y libertades previamente enunciados en su parte dogmática, en el Título I. En donde no sólo revalida los derechos y libertades de sus predecesoras decimonónicas, sino que engrosa esa clásica lista de derechos con los de ejercicio colectivo, confiere a los de sufragio carácter universal y relaciona, en las dos secciones de su Capítulo II, otros destinados a concretar ciertos aspectos del Estado Social que proclama en su artículo primero.

Interesa subrayar este último asunto, porque, en efecto, la Constitución de 1978 aspira a ser la principal herramienta al servicio del bienestar, en el sentido que podía pretenderlo cualquier Constitución histórica, según ha quedado dicho, pero también del modo que reclama su vocación declarada de comunicarle al Estado una dimensión social. Al logro de ese objetivo propenden los artículos 27 y 35 de la constitución, pero también el Capítulo III de su Título I, destinado a enumerar el grueso instrumentos a los que fía la vertebración de ese Estado Social. Los cuales son allí calificados genéricamente como "principios rectores de la política social y económica", e individualizados por tareas cuyo despliegue, en ambos terrenos, se encomienda realizar a los poderes públicos cuando no se concretan en derechos de naturaleza social y económica, apelando, unas y otros, en cualquier caso, a diversas parcelas de bienestar.

Sin duda que el plan para el bienestar enunciado en dicho Capítulo III es ambicioso. En él, los principios rectores de la política social y económica contemplan una realidad ciertamente amplia y rica en matices del bienestar. Por eso se traen a colación, por su utilidad para el estudio del medio ambiente desde una perspectiva jurídica, dado que forman parte, con las disposiciones constitucionales recién citadas, del proyecto social que encierra. En donde el bienestar se erige en protagonista, por serlo tantas parcelas suyas como invocan las disposiciones concernidas cuando describen los escenarios a la espera de actuaciones públicas en lo social.

\subsection{Adhesión estatutaria al plan constitucional del bienestar}

Como cabía esperar que sucediera las Comunidades Autónomas se han mostrado receptivas a este planteamiento constitucional. Así lo revelan las referencias a la calidad de vida o al bienestar de los Estatutos de Autonomía para Andalucía y de Aragón, Cantabria, Castilla-La Mancha, Castilla y León, Cataluña, Extremadura, Islas Baleares, Murcia y Principado de Asturias, ex- 
presadas antes y después del punto de inflexión que ha conocido la evolución del Estado Autonómico en la VIII Legislatura de las Cortes Generales. Aunque las reformas estatutarias efectuadas durante ese período no han podido ser más beneficiosas para este asunto, considerando que han traído consigo, en primer lugar, la incorporación del Estatuto de Autonomía de la Comunidad Valenciana al grupo de los que ya hablaban de la calidad de vida, y, en segundo término, un tratamiento más detenido a su respecto de los Estatutos de Autonomía que ya se ocupaban del particular con anterioridad a su reforma, esto es, del andaluz, el aragonés, el balear, el castellano-leonés y el catalán.

En efecto, antes de la legislatura indicada apelaban al bienestar y a la calidad de vida la Ley Orgánica 6/1981, de 30 de diciembre, de Estatuto de Autonomía para Andalucía ${ }^{26}$, la Ley Orgánica 4/1982, de 9 de junio, Estatuto de Autonomía de Murcia ${ }^{27}$, la Ley Orgánica 1/1983, de 25 de febrero, de Estatuto de Autonomía de Extremadura ${ }^{28}$ y la Ley Orgánica 4/1983, de 25 de febrero, de Estatuto de Autonomía de Castilla y León ${ }^{29}$. Por su parte, mencionaban el bienestar o el bienestar social como objetivo de política social o competencia de la Comunidad Autónoma, respectivamente, la Ley Orgánica 7/1981, de Estatuto de Autonomía del Principado de Asturias ${ }^{30}$, la Ley Orgánica 8/1981, de 30 de diciembre, del Estatuto de Autonomía de Cantabria $^{31}$, la Ley Orgánica 8/1982, de 10 de agosto de Estatuto de Autonomía de Aragón $^{32}$ y Ley Orgánica 2/1983, de 25 de febrero, por la que se aprueba el Estatuto de Autonomía de las Illes Balears ${ }^{33}$. Mientras que invocaban o invocan la calidad de vida como objetivo o valor superior de la vida colectiva autonómica la Ley Orgánica 4/1979, de 18 de diciembre, de Estatuto de Autonomía de Cataluña ${ }^{34}$ y la Ley Orgánica 9/1982, de 10 de agosto, de Estatuto de Autonomía de Castilla-La Mancha ${ }^{35}$.

En lo que a los Estatutos de Autonomía reformados durante la VIII Legislatura de las Cortes Generales se refiere, quizá no sea ocioso señalar cuánta significación le conceden a esa dimensión estructural de Estado social que el

${ }^{26}$ Cfr. sus artículos 12.3 .4 y 12.3 .5 , en donde reciben la consideración de objetivos básicos de la Comunidad Autónoma.

${ }^{27}$ Cfr. el Preámbulo y los artículos 9.2 y 10.1 , en donde calidad de vida y bienestar social son considerados principio rector y competencia exclusiva de la Comunidad Autónoma, respectivamente.

${ }^{28}$ Cfr. sus artículos $1.2,6.2,7.1,14.1$ y 61.6 , en donde son tratados como objetivos de la Comunidad Autónoma y el bienestar social como competencia autonómica.

${ }^{29} \mathrm{Cfr}$. sus artículos 8.3 y 40.1 , dedicados respectivamente a regular el retorno de los emigrantes y los principios rectores de la política económica.

${ }^{30} \mathrm{Cfr}$. el artículo 10.1.24.

${ }^{31} \mathrm{Cfr}$. el artículo 24.

${ }^{32}$ Cfr. los artículos 35.1 y 26.

${ }^{33} \mathrm{Cfr}$. los artículos 16.3, 123.2 y 124.2.

${ }^{34} \mathrm{Cfr}$. el Preámbulo.

${ }^{35}$ Cfr. los artículos 4.4 y 41.1 . 
artículo 1.1 le concede a España. Tanta importancia adquiere allí que, sin exageración, llega a presidir tales Estatutos de Autonomía el afán o la aspiración de contribuir a la construcción de esa faceta del Estado. De ahí que en nada sorprendan sus continuas referencias a la calidad de vida y al bienestar, indiciarias de ese tratamiento detenido que en ellos reciben, bien como principios rectores de las políticas públicas autonómicas, en general, o de las políticas económica, tributaria, de mayores, de menores o de género, por ejemplo, en particular; bien como objetivos básicos de la Comunidad Autónoma, con la invocación, a veces, del Estado de bienestar como telón de fondo, cuando no recibe el bienestar social la consideración de competencia exclusiva ${ }^{36}$.

\subsection{El medio ambiente como objeto de un derecho subjetivo a un bien- estar concreto}

Puesto que ni los trabajos constituyentes sobre el artículo 45 de la Constitución ni su enunciado ofrecen información cierta sobre el significado de la expresión "medio ambiente", se impone, al objeto de obtenerla, ensayar técnicas de aproximación al mismo comúnmente admitidas en Derecho. A cuyo efecto se juzga oportuno combinar la derivada de contemplar la disposición desde la perspectiva inherente a su ubicación constitucional con una interpretación sistemática de sus dos primeros apartados. Pues ambas fórmulas sugieren una precomprensión del medio ambiente en intensa relación con la calidad de vida o el bienestar.

En cuanto al encuadramiento del artículo 45 de la Constitución en su contexto, el Capítulo III del Título I, nada se añadirá a lo ya expresado sobre su consecuencia inmediata: el medio ambiente o, mejor, el derecho al mismo, contribuye a definir el tipo de bienestar humano que allí se fía a la acción del Estado.

Respecto a la interpretación sistemática del artículo 45 de la Constitución cabe afirmar que éste contempla dos clases de vínculos diferenciables entre sí. En virtud del primero anuda a los recursos naturales, de un lado, con la ca-

\footnotetext{
${ }^{36}$ Así, emplean uno y otro término el preámbulo de la Ley Orgánica 1/2006, de 10 de abril, de Reforma de la Ley Orgánica 5/1982, de 1 de julio, de Estatuto de Autonomía de la Comunidad Valenciana. El Preámbulo y los artículos 17, 40, 41.5, 42, 45.2, 53.2, 203.6 y 206.3 de la Ley Orgánica 6/2006, de 19 de julio, de reforma del Estatuto de Autonomía de Cataluña. Los artículos 16.3, 30.15, 123.2 y 124.2 de la Ley Orgánica 1/2007, de 28 de febrero, de reforma del Estatuto de Autonomía de las Illes Balears. El Preámbulo y los artícu$\left.\left.\operatorname{los} 10.3 .6^{\circ}, 10.3 .7^{\circ}, 10.3 .8^{\circ}, 10.3 .14^{\circ}, 18.1,19,37.1 .4^{\circ}, 48.3^{\mathrm{a}}\right) .162 .2,175.2 . c\right), 179.3,201$ y 202 de la Ley Orgánica 2/2007, de 19 de marzo, de reforma del Estatuto de Autonomía para Andalucía. Los artículos 12.2, 23.2.a), 24.a), 99.3 y 107.2 de la Ley Orgánica 5/2007, de 20 de abril, de reforma del Estatuto de Autonomía de Aragón. Y el Preámbulo y los artículos 13.6, 16.2 y 78.1 de la Ley Orgánica 14/2007, de 30 de noviembre, de reforma del Estatuto de Autonomía de Castilla y León.
} 
lidad de vida y el medio ambiente. Mediante el segundo conecta a estos dos últimos bienes, al estimarlos susceptibles de resultar igualmente beneficiados por el uso racional de los recursos naturales. De acuerdo con ello, cabe sostener como hipótesis que en el ideario constitucional los recursos naturales son escasos e ineludible su empleo para la subsistencia humana; como también que medio ambiente y calidad de vida apelan a dos aspectos de un mismo fenómeno, vinculados entre sí mediante la suerte la relación que suele guardar la parte con el todo. En lo que a este último extremo se refiere, se estima aquí, dicho sea en otros términos, que el medio ambiente es una parcela de la calidad de vida o, mejor, del bienestar, tal es el lazo, de cuantos pueden imaginarse anudables entre estos dos últimos bienes, que se juzga aludido por la Constitución el cual tal vez admita identificarse más claramente por los efectos que en ese caso reportaría el cuidado del medio ambiente para la calidad de vida.

Siendo así, resultaría incontrovertible no sólo que el uso racional de los recursos naturales beneficia al medio ambiente, sino también que las acciones públicas tuitivas del medio ambiente, descritas en la norma constitucional, relativas a su defensa y restauración, contribuyen a la protección y mejora de la calidad de vida o el bienestar. En tal supuesto quizá resulte más fácilmente comprensible, además, el protagonismo concedido por el artículo 45.2 de la Constitución a la calidad de vida, congruentemente, por cierto, con el tenor de su contexto inmediato, considerando que el Capítulo III del Título I versa sobre este asunto del bienestar.

Otra cosa es que en todo el Capítulo sólo la mencione ese artículo 45.2, oportunamente, por cierto. Pues adviértase que de los vínculos en los cuales implica la disposición a la calidad de vida, únicamente se detiene a enunciar expresamente aquel mediante el cual queda anudado a ella el uso racional de los recursos naturales, asunto este susceptible de contemplárselo, en principio, como un instrumento útil para conseguir un sinfín de objetivos, en ningún caso evidentes, ni tan siquiera el referido a la protección y mejora de la calidad de vida. De ahí la pertinencia de la precisión constitucional. En su virtud, queda claro que con la racionalidad en el empleo de naturales también se persigue dicha meta.

En cambio, no hay por qué exigirle al artículo 45.2 más elocuencia a la hora de vincular al medio ambiente con este último objetivo, le basta con insinuarlo, pues, con independencia de cual pueda ser el entorno apelado por la expresión, es seguro que su cuidado beneficiará a la calidad de vida. Como lo hará la ejecución de las tareas que el Capítulo III del Título I les encomienda realizar a los poderes públicos en los distintos ámbitos de la realidad que menciona, pues no es dudosa su correspondencia, como en el caso del medio ambiente, con tantas otras parcelas de la calidad de vida o, mejor, del bienestar.

Dígase si no lo evocan por sectores los términos o expresiones siguientes, usados por la Constitución en las dos secciones del Capítulo II, pero mayoritariamente en el Capítulo III de su Título I: seguridad, educación, remuneración suficiente de los trabajadores, progreso social y económico, seguridad 
social, derechos de los emigrantes, salud, cultura, patrimonio, vivienda; atención a la juventud, a los disminuidos físicos, psíquicos o sensoriales, a la tercera edad, a los consumidores y usuarios, a las organizaciones profesionales.

Pero adviértase que la Constitución omite cualquier referencia relativa a los significados de tales voces y locuciones. Todo apunta a que la intencionalidad es evitar la obsolescencia inmediata de las disposiciones constitucionales concernidas, de modo que, como en tantas otras ocasiones, la Constitución da por supuestas las significaciones que omite, incluida la de medio ambiente, cuyo tratamiento no difiere, en consecuencia, del que dispensa a esas otras parcelas de bienestar tratadas en el Capítulo III de su Título I, dejando para el momento de la concretización la tarea de su interpretación diacrónica.

Desde luego que el constituyente español podía adoptar dicho punto de partida, contaba con regulaciones normativas previas clasificables por sectores homogéneos de la realidad susceptibles de apelárselas mediante las denominaciones con que, por entonces, se designaba a estos últimos. Al constituyente le bastaba con invocar esos lugares comunes para indicar a qué se refería y lograr así su objetivo regulador. El medio ambiente no era ninguna excepción a esta regla, pese a tratarse de casi un recién llegado al ordenamiento español de la época que terminó por adquirir carta de naturaleza entre otros conjuntos normativos, ya consolidados, a su costa.

Aunque, pues el Capítulo III, con algunos añadidos del Capítulo II, aspira a lograr el mayor grado de bienestar posible para los ciudadanos, como aquí se sostiene, alguien podría juzgar irrelevante el que una determinada política pública pueda considerarse más beneficiosa para una u otra de las parcelas que cita ese apartado de la Constitución. A la postre, podría pensarse, el desarrollo de esa política contribuirá a ejecutar, en su conjunto, el referido plan constitucional. Ahora bien, la cuestión consistente en ubicar, como mejor proceda, tantos sectores de la realidad, sólo en apariencia medioambientales, adquiere una dimensión distinta cuando se trata de acotar la parcela de bienestar a que apela el medio ambiente, no por puro afán academicista, sino al objeto de obtener un concepto de tal operativo en Derecho.

Interesa, por tanto abordar dicha tarea taxonómica desde el convencimiento de no haber querido decir el constituyente dos veces lo mismo de distinto modo. De donde se sigue que es preciso reconocerle a cada parcela de bienestar la individualidad o entidad propia exigida por cualquier categoría constitucional, aunque sus linderos respectivos puedan mostrarse difusos o imprecisos cuando aquellas se revelen afines o colindantes entre sí. Circunstancia esta que si no obstaculiza la idea de contar con los objetos indiscutibles de otras parcelas de bienestar consignadas en la Constitución, para fijar o individualizar el que pueda corresponderle al medio ambiente, sí que obliga a proceder de acuerdo con un criterio razonable para clasificar los sectores de realidad concernidos por la indagación que aquí se propone efectuar. A cuyo efecto, debe optarse porque sea el de preferir lo específico a lo genérico. 


\subsection{Tentativa de acercamiento al contenido del derecho al medio am- biente}

En resumidas cuentas, atendiendo a su ubicación en el programa sobre el bienestar de la Constitución y a su enunciado, cabe afirmar que con la expresión medio ambiente apela el artículo 45 de la Constitución a un sector de la realidad concreto y específico, distinto de cualquier otro invocado en el Capítulo III de su Título I (incluidos los recursos naturales y, con mayor motivo, la protección de la naturaleza, carente de referencia constitucional alguna) y llamado a convertirse en objeto único del derecho subjetivo allí mencionado. Planteamiento este que así como podrá comprobarse, acaso contradigan algunos tratamientos del medio ambiente plasmados en los Estatutos de Autonomía reformados en la VIII Legislatura de las Cortes Generales, pero que, sin duda, contribuyen a sustentar las regulaciones sobre este particular consignadas en otras normas estatutarias, resultantes de sus reformas respectivas también durante dicha Legislatura.

Alcanzado este punto se impone dar un paso más en torno a qué reclama para sí el derecho al medio ambiente, esgrimible, según ha quedado dicho, como seña identificativa del mismo, frente a las demás porciones de bienestar apeladas por las demás disposiciones integrantes del mencionado Capítulo III del Título I de la Constitución. A cuyo respecto se propone aquí acercarse, nada más todavía, a sus contenidos identificando ese futuro derecho, en primer término, con la situación que permite a sus titulares a vivir tranquila y cómodamente, sin molestias para sus personas ni merma para sus bienes y reaccionar, por tanto, frente a las injerencias en ese estado de cosas imputables a la actividad de terceros.

$\mathrm{Si}$, en segundo lugar, se juzga colindante con el derecho a la salud, como se hace en estas páginas, forzoso será decidir -aunque no se abordará en ellas este asunto-, sobre la mejor ubicación de lo relacionado con la contaminación, por un lado, y reconocer a la vertiente patrimonial del derecho al medio ambiente un contenido diferente y acaso más amplio del que resultaría de identificarlo con su faceta personal exclusivamente. Toda vez que aun cuando no podría asignársele a la Constitución interés alguno por la salud de los animales o plantas si no es por sus posibles consecuencias para la humana o porque unos u otras tengan dueño, es seguro que ciertas propiedades, como las explotaciones forestales pueden sufrir menoscabo sin riesgo ninguno para la salud de nadie.

En relación con el objetivo ahora perseguido, conviene tener en cuenta, por último, el dictado del artículo 45.2 de la Constitución, pues permite sostener que al derecho lo singularizaría además la nota de su vulnerabilidad frente a la acción de los particulares, no de los poderes públicos, quienes, en relación con el mismo, estarían obligados tan sólo a desplegar una actividad de policía preventiva y represiva.

No se ocultará que la caracterización propuesta por el derecho al medio ambiente se inspira en tantas regulaciones europeas sobre el particular de los 
años sesenta. Concretamente de la versión española de éstas representada por el Reglamento de Actividades molestas, insalubres, nocivas y peligrosas. De allí procede la idea de medio ambiente recién propuesta. Aunque no sólo, pues también es tributaria de interpretar sistemáticamente el artículo 45.1 de la Constitución. He aquí el método empleado para dotar de contenido o, al menos, para intentar aproximarse al de un derecho constitucional que, en puridad, no lo es -de serlo sobraría realizar cualquier esfuerzo al respecto- ni siquiera observándolo desde la perspectiva indicada consistente en destacar, de la consideración normativa más tradicional de medio ambiente, la dimensión del mismo que apela al bienestar.

Recuérdese si no la inoperancia de las jurisdicciones ordinaria y constitucional españolas a la hora de tutelar a la familia López Ostra y a Moreno Gómez frente a las molestias que soportaban. En el primer caso debido a la instalación en las inmediaciones del domicilio habitado por dicha familia de una planta de tratamiento de residuos sólidos y líquidos que despedía humos, gases y malos olores. No se olvide que Ayuntamiento ordenó el cese del tratamiento de residuos sólidos, pero permitió que continuase el de aguas residuales; que la familia instó la protección jurisdiccional de los derechos fundamentales, invocando, sin éxito ante la Audiencia Territorial de Murcia, una injerencia ilegitima en su domicilio contraria al goce o disfrute pacífico del mismo, una violación de su derecho a elegir libremente su domicilio y atentados a su integridad física y moral, su libertad y su seguridad (artículos 15, 17.1, 18.2, y 19 de la Constitución); que el Tribunal Supremo desestimó un recurso de apelación interpuesto contra la resolución de la Audiencia, ni que el Tribunal Constitucional, a su vez, declaró inadmisible el recurso de amparo que interpuso, por considerarlo manifiestamente infundado. Con toda lógica, cabe añadir, pues, en puridad, lo reclamado no era subsumible en el contenido esencial de ninguno de los derechos mencionados.

Ante eso, la familia López Ostra recurrió al Tribunal Europeo de Derechos Humanos alegando una violación del artículo 8 del Convenio. El cual constató que "las emanaciones de sulfuro de hidrógeno procedentes de la planta sobrepasaban el límite autorizado", de modo que "podían generar un peligro para la salud de los habitantes de las viviendas próximas y, por último, que podía haber un vínculo de causalidad entre dichas emanaciones y las afecciones que sufría la hija de la demandante". También manifestó el Tribunal que, sin ser responsables de las emanaciones en cuestión las autoridades españolas, en principio, el Ayuntamiento de Lorca permitió la instalación de la planta en unos terrenos que le pertenecían y el Estado concedió una subvención para su construcción y que aun cuando aquél resolvió cerrar parcialmente las instalaciones, sus miembros no podían ignorar que los problemas medioambientales persistieron después de esa medida. Aunque, según precisó el Tribunal, no era importante determinar si el Ayuntamiento había cumplido con lo exigido por el derecho interno, sino dilucidar si "las autoridades nacionales adoptaron las medidas necesarias para proteger el derecho de la de- 
mandante al respeto de su domicilio así como al de su vida privada y familiar garantizados por el artículo 8". En tal sentido, tras afirmar que el Estado demandado no supo mantener "un justo equilibrio entre el interés del bienestar económico de la ciudad de Lorca -el de disponer de una planta depuradoray el disfrute efectivo por la demandante del derecho al respeto de su domicilio y de su vida privada y familiar", que concluyó declarando que se había producido una "violación del artículo 8".

El Tribunal Europeo de Derechos Humanos tuvo la oportunidad de revalidar esta construcción en su Sentencia resolutoria del caso Moreno Gómez contra España, quien denunció ante aquél padecer los ruidos nocturnos procedentes de bares, pubs y discotecas instalados, con autorización municipal, cerca su domicilio en Valencia. Resolución de la que sólo interesa recordar, los siguientes asertos del tribunal:

"El artículo 8 del Convenio protege el derecho del individuo al respeto de su vida privada y familiar, de su domicilio y su correspondencia. El domicilio es normalmente el lugar, el espacio físicamente determinado en donde se desarrolla la vida privada y familiar. El individuo tiene derecho al respeto de su domicilio, concebido no sólo como el derecho a un simple espacio físico, sino también como el derecho a disfrutar en toda tranquilidad de dicho espacio.

"Las vulneraciones del derecho de respeto al domicilio no son solamente las de índole material o corporal, tales como la entrada en el domicilio de una persona no autorizada, sino también las agresiones inmateriales o incorpóreas, como ruidos, emisiones, olores u otras injerencias. Si las agresiones son graves pueden privar a una persona de su derecho al respeto del domicilio porque le impiden gozar del mismo (ver Hatton y otros c. Reino Unido, anteriormente citado $\$ 96)$ )".

Adviértase como mediante tales sentencias el Tribunal Europeo de Derechos Humanos usa una técnica tan heterodoxa como eficaz, para tutelar un derecho de tercera generación concadenándolo a otro de libertad. Pues so pretexto de proteger el domicilio tutelaba, en realidad, por conexión con el mismo, el derecho al medio ambiente, no contemplado en el Convenio. El cual parece concebirlo el Tribunal Europeo de Derechos Humanos como el derecho al bienestar personal que no admite injerencias o intromisiones de terceros no lesivas para la salud ni para ningún bien jurídico integrante del contenido normal atribuible a otro derecho cualquiera, con independencia de su naturaleza. Lo interesante es que el Tribunal Constitucional parece haber aceptado dicha construcción jurisprudencial, si bien es verdad que sin consecuencias. Así, por ejemplo, en la STC 119/2001, de 24 de mayo ${ }^{37}$, manifestó su adhesión a las consideraciones vertidas por el Tribunal Europeo de Derechos Humanos en la Sentencia recaída en el caso López Ostra entre otras,

${ }^{37}$ Cfr. en el mismo sentido la STC 16/2004, de 23 de febrero. 
aunque no sin precisar que había de soslayarse "toda referencia a la hipotética vulneración de aquellos preceptos citados que no figuran entre los comprendidos en la Sección Primera del Capítulo Segundo del Título Primero de la Constitución, cuales son los arts. 9, 10, 33.3, 39.1, 43, 45 y 47 CE"38.

En el mismo sentido, algo más avanzada la Sentencia, puntualizó cómo en el recurso amparo al que ponía término se planteaba "exclusivamente si el nivel de ruidos padecidos por la demandante en su domicilio reviste entidad suficiente para entender que se han vulnerado los derechos fundamentales antes citados. Deben quedar en consecuencia al margen las alusiones efectuadas tanto por la propia demandante como por el Ministerio Fiscal en torno a la degradación del medio ambiente circundante, cuestión reconducible, en su caso, a la esfera propia del art. 45 CE. Dicho de otro modo, debemos dilucidar si han tenido lugar las específicas infracciones constitucionales aquí planteadas por la recurrente y no hemos de pronunciarnos acerca de la calidad de vida existente en el entorno urbano de su vivienda"39.

\section{EL DERECHO AL MEDIO AMBIENTE Y LA PROTECCIÓN DE LA NATURALEZA COMO REALIDADES JURÍDICAS DIFEREN- CIABLES. MENCIÓN DE SUS TRATAMIENTOS ESTATUTARIOS}

Coherentemente con cuanto antecede, se le niega aquí a las normas conservacionistas de cosas, indiscriminadamente, incluidas las de animales y plantas, vínculo alguno con el medio ambiente. Con tanto mayor motivo cuando descansan en el argumento de encontrarse el universo en peligro y precisado de protección por tanto. Toda vez que lejos de estar en peligro se encuentra en el equilibrio inestable consustancial a su movimiento ininterrumpido. De tal modo que nadie, aunque quiera, puede conseguir que el universo devenga estático. Sólo a las normas conservacionistas de cosas estrechamente relacionadas con el bienestar material de las personas, únicos sujetos de derecho, se les reconoce en estas páginas vinculación con lo medio ambiental.

No se negará que sea posible proteger animales y plantas, aisladamente considerados o en interacción, hoy que el Parlamento lo puede todo, incluso convertir a un hombre en mujer. Sería en vano, de no mediar algún obstáculo constitucional -inimaginable en el contexto jurídico cultural español, al menos, e inexistente en la Constitución de 1978, desde luego-, cuando los Estados vienen manifestando un interés creciente por efectuar esta suerte de protección que, además, cada vez con mayor frecuencia, acometen coordinadamente con otros. Tan intensa se advierte esta tendencia o disposición del Estado a proteger la naturaleza que no solo ha contagiado a todas sus instancias -recuérdese si no la importancia que ha tenido en este terreno la construcción

\footnotetext{
${ }^{38} \mathrm{Cfr} . \mathrm{FJ} 4$.
}

${ }^{39}$ Cfr. FJ 4. 
jurisprudencial de la llamada "doctrina de los intereses difusos", por ejemplo-sino que ha traspasado sus fronteras respectivas para instalarse en el seno de las organizaciones internacionales.

Dicha propuesta de construir el derecho al medio ambiente sin la protección de la naturaleza se compadece con el trato diferenciado que han recibido o reciben en algunos Estatutos de Autonomía el medio ambiente y la protección de tantos otros bienes. Pues, en íntima relación con las manifestaciones estatutarias, ya referidas, de adhesión al plan constitucional del bienestar y en ese preciso marco contextual, se sitúan otras susceptibles de estimarse que, en efecto, distinguían o distinguen el medio ambiente de la protección de la naturaleza, por ejemplo.

Tal era el caso de la incluida en la versión derogada del Estatuto de Autonomía para Andalucía, que definía como objetivo básico de la Comunidad Autónoma: "el fomento de la calidad de vida del pueblo andaluz mediante la protección de la naturaleza y del medio ambiente" ${ }^{40}$. Ese mismo juicio merecería, claro está, el dictado idéntico que incluye la versión vigente de dicho Estatuto de Autonomía ${ }^{41}$ si no fuera porque el mismo enuncia además el objetivo de garantizar el derecho al medio ambiente en los siguientes términos literales: "mediante una adecuada protección de la diversidad biológica y los procesos ecológicos, el patrimonio natural, el paisaje, el agua, el aire y los recursos naturales" ${ }^{42}$. Pues resulta evidente que en esta disposición la protección de la naturaleza, lejos de mostrarse una actividad ajena al medio ambiente, contribuye a construir su concepto. Lo que obliga a revisar el significado atribuido a la citada en primer lugar y, con el objeto de conciliarlo con la literalidad de esta última, a efectuar una interpretación sistemática de ambas disposiciones en cuya virtud se concluya que en la Ley Orgánica 6/1981, de 30 de diciembre, de Estatuto de Autonomía para Andalucía, la protección de la naturaleza se revela subordinada a la del medio ambiente, si bien muestra allí la entidad suficiente como para admitir un trato autónomo y diferenciado de ese conjunto que integra.

Otro tanto puede decirse de la Ley Orgánica 5/2007, de 20 de abril, de reforma del Estatuto de Autonomía de Aragón, que, a diferencia del andaluz, no habla del derecho al medio ambiente sino de cuatro derechos "en relación" con el mismo. En concreto, de los relativos "a vivir en un medio ambiente equilibrado, sostenible y respetuoso hacia la salud", "a gozar de los recursos naturales", "a la protección ante las distintas formas de contaminación” y "a

${ }^{40}$ Cfr. el artículo 12.3.5 de la Ley Orgánica 6/1981, de 30 de diciembre, de Estatuto de Autonomía para Andalucía.

${ }^{41}$ Cfr. el artículo $10.3 .7^{\circ}$ de la Ley Orgánica 2/2007, de 19 de marzo, de reforma del Estatuto de Autonomía para Andalucía.

${ }^{42}$ Cfr. Ibíd. Artículo 28.2. El Estatuto de Autonomía andaluz vigente habla, en su artículo 48.3 a), del bienestar animal, incluso, bien que al tratar de la ganadería como sector productivo. 
acceder a la información medioambiental" ${ }^{33}$. Aunque luego, enumera entre sus competencias compartidas con el Estado la protección del medio ambiente, manifestando al respecto que "en todo caso, incluye la regulación del sistema de intervención administrativa de los planes, programas, proyectos, instalaciones y actividades susceptibles de afectar al medio ambiente; la regulación de los recursos naturales, la flora y fauna y la biodiversidad, la prevención y corrección de la generación de los residuos, de la contaminación atmosférica, del suelo y del subsuelo, así como el abastecimiento, saneamiento y depuración de las aguas" ${ }^{44}$.

Idéntico juicio merece la fuente inspiradora de los Estatutos de Autonomía analizados, el catalán, que, como el aragonés y prácticamente en los mismos términos, describe cuatro derechos relacionados con el medio ambiente ${ }^{45}$. Si bien, Ley Orgánica 6/2006, de 19 de julio, de reforma del Estatuto de Autonomía de Cataluña expresa además el compromiso de proteger el medio ambiente con el concurso de "políticas púbicas basadas en el desarrollo sostenible y la solidaridad colectiva e intergeneracional"46; a cuyo propósito añade que tales políticas deben dirigirse a reducir la contaminación ${ }^{47}$, a preservar la naturaleza y la biodiversidad ${ }^{48}$, así como a velar por la cohesión económica y territorial, en el sentido de asegurar "un tratamiento especial de las zonas de montaña, la protección del paisaje, la defensa del litoral, el fomento de las actividades agrarias, ganaderas y silvícolas"49.

Distinto es el caso de la Ley Orgánica 14/2007, de 30 de noviembre, de reforma del Estatuto de Autonomía de Castilla y León que habla de "conservar y proteger el medio ambiente y hacer un uso responsable de los recursos naturales" $"$, en primer lugar, de "vivir en un medio ambiente ecológicamente equilibrado y saludable, impulsando la compatibilidad entre la actividad económica y la calidad ambiental con el fin de contribuir a un desarrollo sostenible" ${ }^{51}$, en segundo término; y de las competencias autonómicas para, de un lado, adoptar "normas adicionales sobre protección del medio ambiente y del paisaje, con especial atención al desarrollo de políticas que contribuyan a mitigar el cambio climático" ${ }^{52}$, y, de otro, proceder al desarrollo legislativo y la ejecución de las normas estatales en materia de protección del medio ambiente y de los ecosistemas, de prevención ambiental, de vertidos a la atmós-

\footnotetext{
${ }^{43}$ Cfr. el artículo 28 del Estatuto vigente de Autonomía de Aragón.

${ }^{44}$ Cfr. Ibíd. Artículo $753^{\mathrm{a}}$.

${ }^{45}$ Cfr. el artículo 27 del Estatuto de Autonomía catalán vigente.

${ }^{46}$ Cfr. Ibíd. Artículo 46.1.

${ }^{47}$ Cfr. Ibíd. Artículo 46.2.

${ }^{48}$ Cfr. Ibíd. Artículo 46.3.

${ }^{49}$ Cfr. Ibíd. Artículo 46.4.

${ }^{50}$ Cfr. el artículo 15.b) del Estatuto de Autonomía Castellano-leonés vigente.

${ }^{51}$ Cfr. Ibíd. Artículo 16.15.

${ }^{52}$ Cfr. Ibíd. Artículo $70.1 .35^{\circ}$.
} 
fera y a las aguas superficiales y subterráneas ${ }^{53}$, por último. De modo que el Estatuto de Autonomía de Castilla y León no parece apelar a un medio ambiente compuesto, entre otros elementos posibles, por el de proteger la naturaleza.

También la Ley Orgánica 1/2007, de 28 de febrero, de reforma del Estatuto de Autonomía de las Illes Balears, se aviene a invocarse como argumento con que sustentar la conveniencia de no acudir a la protección de la naturaleza para dotar de contenido al derecho al medio ambiente. Pues, tras afirmar dicha norma que "toda persona tiene derecho a gozar de una vida y un medio ambiente seguro y sano" 54 , no sólo dice que las autoridades autonómicas "protegerán el medio ambiente e impulsarán un modelo de desarrollo equitativo, territorialmente equilibrado y sostenible" 55 , sino también que "velarán por la defensa y la protección de la naturaleza, del territorio, del medio ambiente y del paisaje" ${ }^{56}$. Planteamiento este que preside el atinente al "fomento y ordenación de la actividad turística", no en balde llamada estatutariamente a compatibilizarse con el "respeto al medio ambiente, al patrimonio cultural y al territorio" 57 . Coherentemente con cuanto antecede, concluye el Estatuto de Autonomía balear, en lo que importa aquí, definiendo como competencias exclusivas autonómicas: la "protección del medio ambiente", la "ecología" y los "espacios naturales protegidos" 58 .

Al grupo integrado por los Estatutos de Autonomía aragonés y balear vendría a sumarse el valenciano que, como ellos, parece referirse a una idea de medio ambiente completa, sin necesidad de acudir para construirla a la acción protectora de la naturaleza. Así, afirma el derecho de toda persona "a gozar de una vida y un medio ambiente seguro, sano y ecológicamente equilibrado" "59; habla de adoptar medidas en el sector agrario conciliables con el mantenimiento "del paisaje, del territorio, del medio ambiente, de la cultura, de las tradiciones y costumbres más definitorias de la identidad valenciana"60; y dice asumir la competencia para el desarrollo legislativo y la ejecución de las normas adoptadas por el Estado sobre protección del medio ambiente ${ }^{61}$.

${ }^{53}$ Cfr. Ibíd. Artículo 71.1.7.

${ }^{54} \mathrm{Cfr}$. el artículo 23.1 del Estatuto balear vigente.

${ }^{55}$ Cfr. Ibíd.

${ }^{56}$ Cfr. Ibíd. Artículo 23.2.

${ }^{57}$ Cfr. Ibíd. Artículo 24.1.

${ }^{58}$ Cfr. Ibíd. Artículo 30.46.

${ }^{59}$ Cfr. el artículo 17.2 de la Ley Orgánica 1/2006, de 10 de abril, de Reforma de la Ley Orgánica 5/1982, de 1 de julio, de Estatuto de Autonomía de la Comunidad Valenciana.

${ }^{60}$ Cfr. Ibíd. Artículo 18.

${ }^{61}$ Cfr. Ibíd. Artículo 50.6. 


\section{DERECHO DE PROPIEDAD VERSUS PROTECCIÓN DE LA NA- TURALEZA}

Del legislador se espera que en su decisión de proteger distintos bienes pondere su respectiva sustantividad. Con tanto mayor motivo cuando puede asistirse a la concurrencia de uno que reúna la consideración de derecho fundamental con un bien jurídico de distinta calidad, como sucedería con la propiedad y, de acuerdo con lo que se lleva dicho, con la naturaleza. De estimarse que la protección de la naturaleza conforma el derecho al medio ambiente, el equilibrio que, necesariamente, habría de buscarse entre ambos derechos fundamentales, exigiría ponderar las circunstancias presentes en cada ocasión. Tarea esta que le corresponde realizar al Tribunal Constitucional. También, desde luego, en la tesis que aquí se sostiene de no formar parte del derecho al medio ambiente la protección indiscriminada de la naturaleza. En tal supuesto es obvio que el contenido esencial del derecho de propiedad operará como límite de la acción protectora desplegable por el legislador sobre la naturaleza. La cual, en definitiva, podrá modular el derecho mencionado hasta donde lo permita la integridad de su contenido esencial.

Sea como fuere se impone el intento, cuando menos, de aproximarse al contenido esencial del mencionado derecho. Acerca del cual, ya a finales del siglo XIX denunciaba Antón Menger como, no obstante declarar la propiedad privada inviolable las Constituciones europeas de la época, a modo de defensa frente a los poderes públicos, aquella conocía cada vez más limitaciones. Harto expresiva de su opinión al respecto es la expresión que usó para rubricar el parágrafo XXXII de su libro El Derecho civil y los pobres: "debilitación interna de la propiedad por la Administración y por el impuesto".

\subsection{Reflexión preliminar decimonónica y lúcida sobre el derecho de pro- piedad y sus limitaciones por el Estado}

Allí sostenía que desde mediados del siglo XIX los Estados europeos habían aumentado su autoridad administrativa y, consiguientemente con ello, si hasta ese momento se habían conducido "dentro de los límites del régimen de la propiedad", desde entonces actuaban de tal manera que "la propiedad y los demás derechos reales hubieron de perder cada vez más su parte substancial". Según añadía, "el arbitrio con que el propietario disponía antes de las cosas, fue luego sustituido por la intervención y cooperación del Estado"62.

Acto seguido señalaba que el Proyecto de Código Civil alemán, a cuyo análisis dedicaba por entero su libro, evitaba dar una fórmula definida al concepto de propiedad. Según sostenía, "dice sólo $($ ( 848) que el propietario tiene

${ }^{62}$ Cfr. El Derecho civil y los pobres. Versión española, con la autorización del autor, realizada por Adolfo Posada. Estudio preliminar sobre Reformismo social y socialismo jurídico por José Luis Monereo Pérez. Granada. Editorial Comares, S.L. 1998, p. 243. 
el derecho de disponer de la cosa libremente, salvo cuando tal derecho estuviese limitado por las leyes o por los derechos de un tercero. Entre tales leyes restrictivas debe comprenderse, según se infiere del Proyecto (...), especialmente la misma legislación administrativa, la cual, según la Constitución del Imperio alemán, se halla principalmente reservada a la competencia de los diversos Estados federales" ${ }^{\prime 3}$.

Quizá podría pensarse, opinaba, que dicha propuesta normativa pondría término a una situación asentada, como regla general, sobre la base de la libre disposición de las cosas por parte del propietario y en la cual la intervención del Estado y de la legislación resultaba ser una excepción relativamente rara. Sin embargo, aclaraba Menger que en rigor no sucedía así. Para él, "a consecuencia del desenvolvimiento del derecho público, el Estado civilizado tiempo ha que no es un amigo desinteresado, un protector, sino un compañero molesto del propietario, que con tono autoritario pretende dominar y usufructuar la propiedad, en unión del propietario. Semejante coparticipación del estado es de un carácter en parte económico y en parte jurídico" 64 .

En el aspecto económico, decía, "el condominio del estado se ejerce mediante la legislación financiera" ${ }^{65}$. Y como la imposición estatal, añadía, "reviste hoy, bajo muchos aspectos, el carácter de un cousufructo del patrimonio nacional, realmente el Estado moderno, mediante su administración, va poco a poco adquiriendo un condominio en la propiedad privada"66. A reglón seguido y a título ejemplificativo mencionaba algunas de las acciones políticas causantes de lo que llamaba una "mayor o menor usurpación respecto de la libre disposición por el propietario de sus bienes". En concreto, citaba al respecto "la policía de los campos, forestal, minera, hidrológica, de calles, industrial, de incendios, edilicia, de higiene, así como el derecho de expropiación forzosa" ${ }^{67}$.

${ }^{63}$ Cfr. Ibíd.

${ }^{64}$ Cfr. Ibíd, p. 244.

${ }^{65}$ En concreto, añadía, "sobre la renta que resulta en trabajo, renta que el propietario obtiene precisamente de los bienes más importantes de la propiedad, el Estado toma siempre la parte del león. Así, por ejemplo, los impuestos que las más importantes ciudades de Austria pagan al Estado y a las Corporaciones políticas, ascienden casi a la mitad de lo que suponen los alquileres, y los otros inmuebles hállanse gravados en igual proporción. La propiedad privada en Alemania no se halla tan gravada como en Austria por el Estado; pero el progresivo desenvolvimiento de la legislación militar y social, llevará a una situación idéntica a los Estados alemanes".Cfr. Ibíd., p. 244.

66 "El sentimiento de soberanía que el dominus romano podía experimentar con razónapostillaba-, hoy es desconocido por el propietario actual. Los propietarios de los inmuebles rústicos, y más todavía los de los urbanos, que forman el núcleo fundamental del patrimonio nacional, son los que precisamente, al usar de su propiedad, van paso a paso seguidos y sometidos por la intervención de la autoridad administrativa”. Cfr., p. 245.

67 "Ni un año pasa en los Estados civilizados -concluía-, sin que el tesoro de las reglas de policía experimente un aumento considerable, que se traduce en crecientes restricciones del dominio del propietario". Cfr. Ibíd., p. 245. 
Pues bien, tras esta exposición proponía Menger que todas estas "restricciones de la propiedad privada", recogidas en normas administrativas, se hiciesen constar en su futura definición del Código civil. En concreto, pretendía sustituir la redacción prevista para el $\S 848$ por otra que atribuyese al propietario de una cosa "el derecho de disponer libremente de la misma, dentro de los límites de la ley, excluyendo a terceros, salvo cuando derechos de terceros justifiquen ciertas restricciones". Tal definición del concepto de propiedad dejaría claro que el propietario podría disponer libremente de la cosa, "sólo dentro de los límites restrictivos, cada vez más restrictivos, de la ley, al modo como un funcionario administrativo, que puede cumplir su función según lo entienda, pero dentro de los límite legales" ${ }^{\circ 8}$.

Resulta perfectamente comprensible el interés de Menger por que el régimen jurídico de la propiedad quedase claramente definido en la norma suprema del ordenamiento jurídico. Bien es verdad que ya lo estaba, pues por entonces desempeñaba la ley esa función, pero había que deducirlo de leyes dispersas y a disposición, recuérdese, de los Estados federales miembros del Impero alemán, además. De ahí que la preferencia de Menger por dejar reflejada su propuesta en el Código civil no obedeciese quizá a una especial consideración del mismo sobre las restantes leyes por la razón que fuera, sino tal vez a que dicho Código en ciernes lo sería en todo el imperio.

\subsection{El contenido esencial del derecho de propiedad en la STC 37/1987, de 26 de marzo}

El tiempo ha terminado por dar la razón a Menger. La suerte de actuación estatal que describe, incidente en la propiedad privada, admite calificársela de embrionaria comparada con la actual. Hoy son más numerosas que a finales del siglo XIX los sectores de la realidad esgrimidos por los Estados como circunstancias habilitantes de su intervencionismo en la propiedad privada y más intenso además.

Por otro lado, es incuestionable que el presente no ha mostrado desapego por que la norma suprema del ordenamiento se manifieste sobre el régimen jurídico de la propiedad. Antes al contrario, las Constituciones europeas vigentes muestran el indiscutible interés por este asunto que expresan sus respectivos tratamientos del mismo. Tan sucintos como cabe esperar de cualquier pronunciamiento constitucional, aunque no tanto que omitan mencionar como parte integrante de dicho régimen jurídico el referido intervencionismo del Estado. Al menos, no es el caso de la Constitución española de 1978, que se ocupa de este particular en su artículo 33. El cual, enuncia en el apartado primero "el derecho a la propiedad privada y a la herencia"; establece en el apartado segundo que "la función social de estos derechos delimitará su con-

${ }^{68}$ Cfr. Ibíd., p. 246. 
tenido, de acuerdo con las Leyes"; y garantiza en el apartado tercero que "nadie podrá ser privado de sus bienes y derechos sino por causa de utilidad pública o interés social, mediante la correspondiente indemnización y de conformidad con lo dispuesto en las Leyes".

Acerca de tales disposiciones interesa traer a colación las consideraciones que les dedica la STC 37/1987, de 26 de marzo, en los prolegómenos de la construcción que allí ofrece sobre el contenido esencial de derecho a la propiedad. Pues, efectivamente, encabeza el Tribunal sus formulaciones al respecto con un recordatorio de su doctrina sobre el contenido esencial de los derechos ${ }^{69}$, previo a una llamada de atención sobre la inviable separación artificiosa de esos tres apartados del artículo 33 de la Constitución, los cuales, insistía, vistos en su conjunto revelan la naturaleza del derecho en cuestión. En concreto, decía, se trata de un trata de un "derecho reconocido, como ha declarado este Tribunal en la Sentencia 111/1983 (fundamento jurídico $8^{\circ}$.), desde la vertiente institucional y desde la vertiente individual, siendo, desde este último punto de vista, un derecho subjetivo que "cede para convertirse en un equivalente económico, cuando el bien de la comunidad... legitima la expropiación", concluía. Y verdaderamente la propiedad ha evolucionado de tal modo que, sin dejar de ser un derecho individual y, por tanto, subjetivo, es también una institución jurídica de naturaleza objetiva, sujeta en cuanto tal al complimiento de la función social que la Constitución le encomienda desempeñar.

Tras estas consideraciones iniciales calificaría el Tribunal a la función social de la propiedad, con base en la mención que le dedica el artículo 33.2 de la Constitución, como "elemento estructural de la definición misma del derecho a la propiedad privada o como factor determinante de la delimitación legal de su contenido" "70. Por ello, añadía, "la fijación del 'contenido esencial'

\footnotetext{
${ }^{69}$ A este respecto manifestaba que "la determinación del contenido esencial de cualquier tipo de derecho subjetivo -y, por tanto, también de los derechos fundamentales de las personas- viene marcada en cada caso por el elenco de «facultades o posibilidades de actuación necesarias para que el derecho sea recognoscible como perteneciente al tipo descrito y sin las cuales deja de pertenecer a ese tipo y tiene que pasar a quedar comprendido en otro, desnaturalizándose, por decirlo así. Todo ello referido al momento histórico de que en cada caso se trata y a las condiciones inherentes en las sociedades democráticas, cuando se trate de derechos constitucionales». Determinación que, desde otro ángulo metodológico no contradictorio ni incompatible con aquél, puede ser expresada como «aquella parte del contenido del derecho que es absolutamente necesaria para que los intereses jurídicamente protegibles, que dan vida al derecho, resulten real, concreta y efectivamente protegidos. De este modo, se rebasa o se desconoce el contenido esencial cuando el derecho queda sometido a limitaciones que lo hacen impracticable, lo dificultan más allá de lo razonable o lo despojan de la necesaria protección. (Sentencia 11/1981, de 8 de abril, fundamento jurídico 10.)" Cfr. STC 37/1987, 26 de marzo, F. J. 2.

${ }^{70}$ Para el Tribunal, en efecto, esa referencia a la función social de la propiedad que realiza el citado artículo de la Constitución, evidencia que ésta "no ha recogido una concepción abstracta de este derecho como mero ámbito subjetivo de libre disposición o señorío sobre el
} 
de la propiedad privada no puede hacerse desde la exclusiva consideración subjetiva del derecho o de los intereses individuales que a éste subyacen, sino que debe incluir igualmente la necesaria referencia a la función social, entendida no como mero límite externo a su definición o a su ejercicio, sino como parte integrante del derecho mismo. Utilidad individual y función social definen, por tanto, inescindiblemente el contenido del derecho de propiedad sobre cada categoría o tipo de bienes"71.

Consideraba además el Tribunal la incorporación de exigencias sociales al contenido del derecho de propiedad, habilitantes de intervenciones no ablatorias de facultades y responsabilidades al propietario, "un hecho hoy generalmente admitido", coincidente con la imagen que de aquel derecho se ha formado la sociedad contemporánea y conforme con principios e intereses contemplados y tutelados constitucionalmente ${ }^{72}$. En tal sentido, traía a colación los enunciados de los artículos 128.1,40, 45 y 130 de la Constitución, por este orden, para sustentar en ellos la conclusión de corresponderle a los poderes públicos, competentes en cada caso, definir el derecho de propiedad en relación con cada tipo de bienes, aunque no sin recordar al respecto que dicha tarea se aviene a ser controlada por las jurisdicciones ordinaria y constitucional, en orden a verificar su acomodación al contenido esencial o mínimo de la propiedad privada, entendido éste como canon para "la recognoscibilidad de cada tipo de derecho dominical en el momento histórico de que se trate" y para "la practicabilidad o posibilidad efectiva de realización del derecho, sin que las limitaciones y deberes que se impongan al propietario deban ir más allá de lo razonable"73.

Aún completaba el Tribunal sus consideraciones hasta aquí referidas de la STC 37/1987, con otras dos de interés para estas páginas. Dedicaba la primera a los cambios que en su doble vertiente, como institución y como derecho individual, ha conocido a lo largo del siglo XX la propiedad privada. Tan profunda estimaba la transformación experimentada por ésta, que rechazaba

bien objeto del dominio reservado a su titular, sometido únicamente en su ejercicio a las limitaciones generales que las Leyes impongan para salvaguardar los legítimos derechos o intereses de terceros o del interés general. Por el contrario, la Constitución reconoce un derecho a la propiedad privada que se configura y protege, ciertamente, como un haz de facultades individuales sobre las cosas, pero también, y al mismo tiempo, como un conjunto de deberes y obligaciones establecidos, de acuerdo con las Leyes, en atención a valores o intereses de la colectividad, es decir, a la finalidad o utilidad social que cada categoría de bienes objeto de dominio esté llamada a cumplir". Cfr. Ibíd.

${ }^{71}$ Cfr. Ibíd.

${ }^{72}$ Por ende, apostillaba, "debe ser rechazada la idea de que la previsión legal de restricciones a las otrora tendencialmente ilimitadas facultades de uso, disfrute, consumo y disposición o la imposición de deberes positivos al propietario hagan irreconocible el derecho de propiedad como perteneciente al tipo constitucionalmente descrito". Cfr. Ibíd.

${ }^{73}$ Cfr. Ibíd. 
la posibilidad de concebírsela como hoy "como como una figura jurídica reconducible exclusivamente al tipo abstracto descrito en el art. 348 del Código Civil". En su opinión, "la progresiva incorporación de finalidades sociales relacionadas con el uso o aprovechamiento de los distintos tipos de bienes sobre los que el derecho de propiedad puede recaer ha producido una diversificación de la institución dominical en una pluralidad de figuras o situaciones jurídicas reguladas con un significado y alcance diversos. De ahí que se venga reconociendo con general aceptación doctrinal y jurisprudencial la flexibilidad o plasticidad actual del dominio que se manifiesta en la existencia de diferentes tipos de propiedades dotadas de estatutos jurídicos diversos, de acuerdo con la naturaleza de los bienes sobre los que cada derecho de propiedad recae"74.

En cuanto al segundo grupo de consideraciones jurisprudenciales anunciadas, de las que interesa dar cuenta, versan sobre el grado de afectación que han conocido las propiedades como consecuencia de la transformación evolutiva del derecho descrita por el Tribunal. Quien estimaba más intensa la restricción o modalización de las facultades dominicales y la imposición de deberes positivos al titular, en el caso de la propiedad inmobiliaria, urbanística, agrícola o forestal. En esta premisa sustentó el Tribunal su análisis de la propiedad agraria y el contenido esencial de la misma, que iniciaba inmediatamente a continuación de enunciar el postulado, negando, consecuentemente con él, al silencio de la Constitución sobre esa clase de propiedad -ciertamente llamativo comparado con la mención en los artículos 45 y 47 de otros bienes inmuebles o de los recursos naturales-, el significado de impermeabilidad frente a las modulaciones y cambios que ha venido conociendo el instituto de la propiedad privada en general y de la propiedad agraria en particular ${ }^{75}$.

Del discurrir posterior de la STC 37/1987, por los derroteros del referido análisis sobre el alcance de esta última suerte de propiedad, interesa destacar, en primer lugar, el rechazo del Tribunal a entender que pudiera infringir su contenido esencial la regulación legal limitadora de las facultades del propietario, relativas al uso, destino y aprovechamiento de los fundos rústicos que "imponga a éste o permita imponerle determinados deberes de explotación y, en su caso, de mejora, orientados a la obtención de una mejor utilización productiva de la tierra, desde el punto de vista de los intereses generales, siempre que quede salvaguardada la rentabilidad del propietario o de la empresa agraria" ${ }^{\prime 6}$. Y, en segundo término, merece subrayarse también la negativa del Tribunal a estimar vulnerado el contenido esencial de la propiedad agraria por la suerte de expropiaciones contempladas en la Ley 8/1984, de 3

\footnotetext{
${ }^{74}$ Cfr. Ibíd.

${ }^{75}$ Cfr. Ibíd.

${ }^{76}$ Cfr. Ibíd.
} 
de julio, de Reforma Agraria, del Parlamento de Andalucía, como sanción al incumplimiento de la función social de la propiedad de la tierra. Según afirmaba, "no sería constitucional una expropiación que, afectando parcialmente a algunas de las facultades del propietario reconocidas por la Ley, privase en realidad de todo contenido útil al dominio sin una indemnización adecuada a esta privación total del derecho, que puede, desde luego, medirse desde el punto de vista del aprovechamiento económico o rentabilidad de la nuda propiedad o de las facultades que el propietario conserve tras la operación expropiatoria, teniendo siempre en cuenta que tal utilidad individual o tales facultades no pueden ser absolutas e ilimitadas, en razón de las exigencias de la función social de la propiedad". En su opinión, además, la privación de las facultades de uso y disfrute no supondría, por sí misma, una ablación plena de la propiedad, como lo demuestra, añadía, "el hecho de que tales facultades son domino volente perfectamente separables de la titularidad del propietario y enajenables a un tercero, sin que por ello pierda aquél su señorío sobre el bien. Por lo demás este tipo de expropiación no plena está reconocido y regulado en nuestro ordenamiento por la vigente Ley de Expropiación Forzosa" "77.

\section{3. ¿Primacía del valor de uso sobre el valor de cambio?}

Le asiste la razón al Tribunal Constitucional cuando afirma, de un lado, que la función social de la propiedad es parte integrante del derecho y, en íntima relación con ello, de otro, constata la existencia de diferentes tipos de propiedad catalogables, entre otros posibles criterios, con arreglo al de las "finalidades sociales relacionadas con el uso o aprovechamiento de los distintos tipos de bienes sobre los que el derecho de propiedad puede recaer".

Ciertamente los tiempos que corren no invitan tanto a hablar de la propiedad como de las propiedades. Una de las más significadas entre las inmobiliarias es la rústica, susceptible de subdividirse a su vez en varias categorías según el tipo de explotación a que se dedique: agrícola, forestal, ganadera, cinegética, minera, lúdica, turística, etc. Las cuales suelen ser objeto de actuaciones públicas limitadoras, cuando no ablatorias de dicho uso. Por eso se traen a colación tales propiedades, porque el género al que usualmente se adscriben, el de la propiedad rústica, se aviene a ser declarado "espacio natural protegido".

La Ley 42/2007, de 13 de diciembre, del Patrimonio Natural y de la Biodiversidad, podía haber resuelto muchas cosas, haber dejado atrás los tiempos en que se debatía respecto al reconocimiento o no de un ius expropiandi al propietario del bien rústico declarado espacio natural. Debate que propiciaron, sin duda, pronunciamientos como el de la STC 170/1989, de 19 de octubre,

${ }^{77}$ Cfr. F. J. 4. 
en donde rechazó el Tribunal que la Ley de la Comunidad Autónoma de Madrid, 1/1985, de 23 de enero, del Parque Regional de la Cuenca Alta del Manzanares, contemplara privación de propiedad alguna de los terrenos incluidos en dicho parque o de cualquier otro derecho indemnizable, y, por consiguiente, ninguna medida ablatoria del derecho de propiedad.

Para el Tribunal, la Ley realizaba, eso sí, "una configuración de los derechos existentes sobre dichos terrenos que, sin perjuicio de lo que posteriormente se dirá, no supone en si misma privación de propiedad alguna, ni de bienes y derechos patrimoniales, sino sólo el establecimiento de las limitaciones generales y específicas que respecto de los usos y actividades hayan de establecerse en función de la conservación de los espacios y especies a proteger. No cabe duda, por otra parte, que si las exigencias que impone la protección de los espacios naturales llevara al poder público a estimar necesaria la expropiación, ésta se vería obviamente sujeta a la legislación vigente en materia de expropiación; y lo mismo ha de decirse en relación con cualquier otra limitación singular de un derecho patrimonial susceptible de provocar daños que aunque legítimos deban ser objeto de resarcimiento"78. Según el Tribunal, además, Las limitaciones del derecho de propiedad que introduce la Ley madrileña con carácter no indemnizable no vulneran el contenido esencial de los derechos afectados, al tratarse de medidas tendentes a proteger el espacio natural, según la distinta calificación del terreno y en cumplimiento del mandato que impone el art. 45 C.E." 79.

Como señala López Ramón, apoyándose en esta cita jurisprudencial, precisamente, la declaración de un espacio natural protegido no conlleva, necesariamente, con carácter general, la privación de facultades que caracterizan al derecho de propiedad ${ }^{80}$. En su opinión -que aquí se comparte-, el artículo 39.1 de la Ley 42/2007, de 13 de diciembre ${ }^{81}$, además, se limita a "permitir el

${ }^{78}$ Cfr. STC 170/1989, de 23 de enero, F.J.8.

${ }^{79}$ Cfr. Ibíd.

80 “Algunas expectativas del propietario - continúa- pueden quedar alteradas al declararse el espacio, como sucede normalmente con las relativas al eventual aprovechamiento urbanístico de la propiedad o a otras actividades económicas, pero no parece exacto sostener que todo aprovechamiento agrario quede directamente eliminado, y hay incidencias sobre las propiedades privadas que sólo se producen en determinados espacios naturales o en ciertas zonas de los mismos". Cfr. López Ramón, Fernado, "El régimen de las indemnizaciones por las privaciones singulares derivadas de la legislación de conservación de la biodiversidad". Actualidad Jurídica Ambiental.http://actualidadjuridicaambiental.files.wordpress.com/2009/06/ lopezramon-aja28062009.pdf.

${ }^{81}$ Según el cual: "La declaración de un espacio natural protegido lleva aparejada la declaración de utilidad pública, a efectos expropiatorios de los bienes y derechos afectados, así como la facultad de la Comunidad autónoma para el ejercicio de los derechos de tanteo y de retracto respecto de los actos o negocios jurídicos de carácter oneroso y celebrados intervivos que comporten la creación, transmisión, modificación o extinción de derechos reales que recaigan sobre bienes inmuebles situados en su interior". 
ejercicio de la potestad de expropiación forzosa para el cumplimiento de los fines de los espacios naturales", de igual modo que lo permitían, añade, los artículos 3 y 10.3 de la Ley de Conservación de 1989 y lo permite también el artículo 13.1 de la Ley 5/2007, de 3 de abril, de Red de Parques Nacionales ${ }^{82}$.

Por su parte, la actitud de la jurisdicción contencioso-administrativa ante las privaciones singulares anudables a la declaración de un espacio natural es tan elocuente como lo revela la manifestación efectuada por el Tribunal Supremo, luego de entrar en vigor la Ley 42/2007, en su sentencia de 30 de abril de 2009. Téngase presente que allí ha reconocido el derecho a indemnización por la completa prohibición de los aprovechamientos cinegéticos, agrícolas y ganaderos establecida en el plan de ordenación de los recursos naturales de un espacio natural protegido porque: "no constituyen una mera limitación de su uso, que vendría a definir el contenido normal de la propiedad y a configurar su peculiar estatuto jurídico, sino que supone una restricción singular de esos aprovechamientos por razones de utilidad pública, que no deben ser soportados por la persona desposeída sin la indemnización correspondiente, pues en otro caso se vulnerarían el artículo 33 de la Constitución Española y los artículos 349 del Código Civil y $1^{\circ}$ de la Ley de Expropiación Forzosa, que son los infringidos por la Sala de instancia al haber desestimado el recurso contencioso administrativo" $"$.

En esto ha consistido el control efectuado sobre las declaraciones de espacios naturales protegidos por las jurisdicciones constitucional u ordinaria, en determinar si el grado de afectación soportado por las propiedades concernidas, como consecuencia de la acción pública de que se trate, vulnera o no el contenido esencial o mínimo del derecho, para, según el caso, revalidar o corregir la decisión de hacer recaer en sus titulares la carga concatenada a la declaración correspondiente.

Hasta el momento no parece ser objeto de debate que la protección de la naturaleza pueda limitar el derecho de propiedad ni que su titular haya de soportar alguna de las cargas que eso conlleva. Basta con que el legislador declare esa protección vinculada, como cualquier otra, al cumplimiento de una función social para zanjar todo discusión en torno a este asunto. Pero ¿no debería este derecho constitucional, en tanto que tal, mostrarse más resistente frente a la acción de los poderes públicos, incluido el legislador, cuando se trata de proteger la naturaleza?

No se discute aquí que, en ocasiones, dicha tarea cumpla una función social de primer orden, recuérdense si no los perjuicios derivados de la destrucción del bosque para la agricultura y la ganadería. Sin embargo, de ahí a sostener que la protección de la naturaleza esté justificada, por sí misma, media un largo trecho que no ayuda a recorrer el silencio absoluto de la Cons-

\footnotetext{
${ }^{82} \mathrm{Cfr}$. El régimen de las indemnizaciones por las privaciones singulares derivadas de la legislación de conservación de la biodiversidad. Cit. Ibíd.

${ }^{83}$ La cita ha sido extraída del trabajo, varias veces citado, de López Ramón.
} 
titución en torno a este asunto ${ }^{84}$. Interesa subrayarlo porque su colisión con el derecho fundamental de propiedad movería a efectuar una ponderación de bienes en presencia que, por la distinta calidad de los mismos, acaso resulte más ventajosa para el derecho, en el sentido de propiciar, con carácter general, como solución preferente la expropiatoria. Tal vez eso contribuyese además a revisar el actual entendimiento del derecho de propiedad, tan maleable por la acción pública protectora de la naturaleza, de tal modo que a la postre estimulase a realizar un uso restringido de la misma.

Quizá hubiera sido razonable proponer aquí una suerte de equilibrio distinto del indicado entre el derecho de propiedad y la conservación de la naturaleza, de haberle prestado la Constitución a esta última alguna atención. Sin embargo, el mutismo de aquella a su respecto no le depara siquiera el respaldo de la garantía constitucional que oponer al del contenido esencial del derecho por reducido que pueda ser su ámbito.

Desde luego que nada tiene de particular la pretensión de negar dicho silencio constitucional con el argumento de entenderse invocada la protección de la naturaleza en la mención del medio ambiente. Claro que vista aquella desde la perspectiva en cuya virtud reclamaría considerársela como una parte de éste, a despecho de comprometer seriamente, según viene señalándose, la tarea de construir un derecho al medio ambiente. Idéntica función argumental, subordinada al servicio del propósito indicado, desempeñaría igualmente pretender bien que cuanto se avenga a estimarse naturaleza es un recurso natural o bien que protegiendo la naturaleza se contribuye al bienestar de las personas. Debido, en el primer caso, a la convocatoria de los recursos naturales, por el artículo 45.2 de la constitución, para su utilización racional; y, en segundo, a que el bienestar o, tanto da, la calidad de vida, es expresamente llamada por esa misma disposición a protegerse.

Interesa subrayarlo porque de estos dos últimos planteamientos se hace eco la Ley 42/2007, de 13 de diciembre, del Patrimonio Natural y de la Biodiversidad. Considérese al respecto que su artículo 3.30 identifica a los recursos naturales con "todo componente de la naturaleza, susceptible de ser aprovechado por el ser humano para la satisfacción de sus necesidades y que tenga un valor actual o potencial, tales como: el paisaje natural (...)" ${ }^{\prime 5}$. Mien-

\footnotetext{
${ }^{84}$ En cambio, la Constitución sí habla de proteger las modalidades lingüísticas de España (artículo 3.4), la juventud y la infancia (artículo 20.4), la familia (artículo 39.1), los hijos (artículo 39.2), los niños (artículo 39.3), la salud (artículo 43.1), el medio ambiente (artículo 148.1.9 y 149.1.23), los edificios e instalaciones de las Comunidades Autónomas (artículo 148. 1.22) y el interés general de España (artículo 155).

85 “ (...) las aguas, superficiales y subterráneas; el suelo, subsuelo y las tierras por su capacidad de uso mayor: agrícolas, pecuarias, forestales, cinegética y de protección; la biodiversidad; la geodiversidad; los recursos genéticos, y los ecosistemas que dan soporte a la vida; los hidrocarburos; los recursos hidroenergéticos, eólicos, solares, geotérmicos y similares; la atmósfera y el espectro radioeléctrico, los minerales, las rocas y otros recursos geológicos renovables y no renovables", concluye dicho artículo 3.30 de la Ley 42/2007, de 13 de diciembre.
} 
tras que su artículo 4.1 reitera la afirmación del Preámbulo según la cual: “el patrimonio natural y la biodiversidad desempeñan una función social relevante por su estrecha vinculación con el desarrollo, la salud y el bienestar de las personas y por su aportación al desarrollo social y económico".

Desde Luego no se negará que merezca la consideración de recurso natural cualquier cosa procedente de la naturaleza susceptible de aprovechamiento para satisfacer las necesidades humanas. Al recurso natural ha de exigírsele, por tanto, que tenga valor de cambio. Consúltese si no el Diccionario de la Real Academia, según el cual, recuso, natural o no, es el "conjunto de elementos disponibles para resolver una necesidad o llevar a cabo una empresa"; y téngase en cuenta además que, de acuerdo con este significado adquieren plenitud de sentido no sólo el enunciado del artículo 45.2, sino también el tratamiento de los recursos naturales como bienes de dominio público por el artículo 132.2, no en balde ubicado en el Título III de la Constitución, precisamente dedicado a regular la economía y la hacienda, recuérdese. No se diga entonces que recurso natural es cualquier cosa con valor actual o potencial -salvo que quiera apelarse con ambos términos al valor de cambio- ni se afirme tampoco que sea un recurso natural el paisaje, tal vez provisto de valor de uso, pero no de cambio, abstracción hecha, claro está, de lo que cueste su declaración para los propietarios de los bienes afectados.

Pero, si el artículo 3.30 de la Ley 42/2007, de 13 de diciembre, fuerza de este modo el recto entendimiento del lenguaje y aun de las categorías jurídidico-constitucionales, también lo hace el artículo 4.1. Pues, dígase en qué beneficia a las personas la declaración de una Zona de Especial Protección de las Aves, como las avutardas, por ejemplo. Acaso el bienestar de tales aves quede asegurado con ello, pero, según ha quedado dicho, el de las personas es otra cosa.

De ahí que, en casos como éste, resulte tanto más encomiable la actitud de los poderes públicos tendente a cerrar los acuerdos voluntarios que aconseja adoptar dicha Ley en su artículo 4.3, entre la Administración actuante y los propietarios de los recursos naturales, en este supuesto las fincas rústicas afectadas por las limitaciones de uso consustanciales a la declaración de una Zona de Especial Protección de las Aves. De este modo podrá paliarse, cuando menos parcialmente, esa consecuencia adherida a la declaración del señalado espacio natural protegido, es decir, el menoscabo que significa, no para los bienes inmuebles concernidos, claro está, sino para sus dueños, sujetos de derecho, la decisión de beneficiar a bienes sin dueño y objetos de derecho, las avutardas.

Pues bien, respecto de la modalidad de espacio natural protegido señalada, muestra, por una parte, la Ley 42/2007, de 13 de diciembre, tanto interés como evidencia su tratamiento autónomo y pormenorizado de la figura; $\mathrm{y}$ las administraciones públicas autonómicas, llamadas a emplearla, por otra, la predilección por la misma que revela la frecuencia de su empleo. Circuns- 
tancias ambas perfectamente comprensibles, considerando cuánto han significado para España las Zonas de Especial Protección para las Aves, susceptibles de considerarse las teselas del mosaico conocido como la "red ecológica 2000" ${ }^{\circ 6}$, del cual LIFE + es su instrumento financiero. Téngase presente que hasta 2006 el programa LIFE-Naturaleza ha cofinanciado en España 188 proyectos, lo que representa una inversión estimada de 226,8 millones de euros, de los que 98,6 corresponden a la Unión Europea ${ }^{87}$, y que el presupuesto de LIFE +, para el período comprendido entre el 1 de enero de 2007 y el 31 de diciembre de 2013, asciende a 2.143.409.000 euros ${ }^{88}$.

${ }^{86}$ Regulada, en lo que se refiere a las aves, por las Directivas 79/409/CEE y 91/244/CEE, así como por la Ley 42/2007, de 13 de diciembre, en sus artículos 41 a 48 .

${ }^{87} \mathrm{Cfr}$. http://ec.europa.eu/environment/countries/documents/spain_es_nov06.pdf.

${ }^{88} \mathrm{Cfr}$. http://europa.eu/legislation_summaries/agriculture/environment/128021_es.htm. 